\title{
Review on Hybrid Carbon/Flax Composites and Their Properties
}

\author{
Madina Shamsuyeva $\mathbb{D}^{\mathbb{D}}$, Ole Hansen, and Hans-Josef Endres \\ Application Center HOFZET, Fraunhofer Institute for Wood Research WKI, Hanover 30453, Germany \\ Correspondence should be addressed to Madina Shamsuyeva; madina.shamsuyeva@wki-extern.fraunhofer.de
}

Received 26 March 2019; Revised 8 July 2019; Accepted 9 August 2019; Published 8 September 2019

Guest Editor: Basim Abu-Jdayil

Copyright (C) 2019 Madina Shamsuyeva et al. This is an open access article distributed under the Creative Commons Attribution License, which permits unrestricted use, distribution, and reproduction in any medium, provided the original work is properly cited.

\begin{abstract}
Numerous research studies are carried out in order to investigate various properties and implement the potential of hybrid carbon/flax composites for technical applications. This review aims to present a summary of materials and manufacturing techniques, which are currently used for the fabrication of the carbon/flax composites, and describe the reported tensile, bending, impact, and damping properties of the resulting hybrid materials as well as the attempts to model some of these properties.
\end{abstract}

\section{Introduction}

In the recent years, promoted by the growing environmental awareness, the effective use of renewable resources in numerous lightweight applications gained the attention of scientists and industry. In this context, natural fiberreinforced polymer composites have already validated their beneficial properties for use in selected structural components in the automotive and sport industries [1-5]. As an example, besides a better ecological performance, in comparison with synthetic fiber composites, like glass fiber composites, natural fiber composites offer lower density and compared with carbon fiber composites better damping properties. However, natural fiber composites show lower mechanical performance than the synthetic fiber composites. Currently, this drawback of the natural fiber composites limits their applications to structural components subjected to a minor mechanical loading, like, e.g., automotive interiors $[2,3]$. Hybridisation of natural and synthetic fibers in one composite is a promising solution to combine the benefits of the individual fiber types in one hybrid composite and develop new materials with an optimal compromise between material properties and environmental aspects. One of the first reports on hybrid natural/synthetic fiber polymer composites containing pineapple leaf/sisal/glass fiber-reinforced polyester was published around 15 years ago [6]. Since that time onwards, this field shows a dynamic growth and numerous hybrid composites contain- ing diverse combinations of fibers are described in the literature [7]. At the same time, until the recent years, predominantly, glass fibers were used as a synthetic fiber type in these hybrid composites. The widespread use of glass fibers is promoted by their high mechanical performance associated with a high density and low cost. Therefore, the hybridisation of glass and natural fibers enables manufacture of cost-effective hybrid composites demonstrating an optimal mechanical performance-to-weight ratio.

However, in the last 5 years, the potential of the hybridisation of flax with high-performance expensive carbon fibers has been actively investigated. This type of hybridisation is especially interesting for the fields where mechanical performance and low weight are more significant than the cost of the corresponding construction part, like, e.g., sport and leisure [8], orthopaedic implants [9], or the automotive, especially racing car, industry $[10,11]$.

The aim of this study is to provide a review about the progress in the field of the carbon/flax hybrid composites, i.e., to describe components and techniques used for the manufacture of these hybrid composites and analyze the predicted and experimentally achieved mechanical properties, namely, tensile, flexural, impact, and damping properties. The dynamically growing application-oriented research on the carbon/flax polymer composites is actively supported by the industry. On the one hand, this support promotes rapid marketing of the developed hybrid composites. On the other hand, due to nondisclosure agreements or commercial 
reasons, the industry support may inhibit or hinder the publication of the experimental results. Consequently, this review focuses mainly on the reported studies on carbon/flax composites, and it is important to consider that the overall number of the realized studies on this type of hybrid materials is significantly higher.

Table 1 presents an outline of the main results of the reviewed studies on carbon/flax polymer composites published during the last seven years. In addition, Table 2 summarizes chronologically the main research issues of these studies.

The overview in Table 1 shows that the number of studies carried out in the field of carbon/flax fiber composites and the diversity of the studied scientific questions are raising with time. At the same time, the studies dealing with diverse composite constituents, like, e.g., different fiber forms or stacking sequences, end up with the conclusion that in comparison with other parameters, the amount of the used carbon and flax fibers and the stacking sequence significantly affect the properties of the resulting hybrid composites. Furthermore, various modelling approaches used to predict mechanical and damping properties show good agreement with the experimental results. Finally, in the newest studies, the application-oriented potential of the carbon/flax composites is evaluated with regard to the selected construction parts, which are produced commercially using metals as raw material. The results show that the hybrid composites show comparable or even higher mechanical performance than the same parts made of aluminium.

Table 2 shows that the reported studies focus mainly on the understanding and prediction of the mechanical performance of the hybrid composites, characterization of their properties, and possibilities to effectively integrate new fiber types.

\section{Hybrid Composites and Their Properties}

In general, the use of composite materials for various technical applications is an effective approach due to the diversity of the existing composite constituents and, therefore, a wide range of the offered composite properties, especially the mechanical properties. Similarly, as in the case of nonhybrid fiber-reinforced plastics, the design of the hybrid fiber composites is subject to Puck's failure criteria: breaking strength and stiffness of the used fiber types must be greater than those of the polymer matrix and the matrix must have higher elongation at break than the fibers [28]. Furthermore, the fundamental mechanical processes taking place in a nonhybrid composite, like, e.g., load distribution from matrix to fibers and failure mechanisms, are also valid for the hybrid fiber composites. However, the failure mechanisms of the hybrid composites are more complex and specific due to the high variation of the constituents and the processing parameters. This study presents various approaches used to combine carbon and flax fibers in one hybrid composite. The simplest of these approaches is the so-called "hybrid interply" [29], i.e., a stacking sequence, where stiff carbon fabrics are positioned at the outer layers and more elastic flax fibers at the inner layers of the hybrid composite, Figure 1.
This approach follows the classical "sandwich-structured composite" method, where two thin, but stiff, skins are attached to a lightweight but thick core, like, e.g., metal sheets attached to a polyurethane core. Consequently, similar to the sandwich-structured composites, the hybrid interplies offer especially high bending properties. The behaviour of the sandwich-structured composites and further hybrid synthetic fiber composites is extensively described in the literature using various models and experimental results $[29,30]$.

However, the hybridisation of flax and carbon fibers has been investigated merely on the basis of individual hybrid composites. Consequently, there is a demand for a systematic review of the properties of these hybrid composites and their dependence on the constituents and manufacturing process.

Figure 1 represents a CAD model of flax textile sandwiches between two carbon fiber textiles. Furthermore, this figure summarizes the most important parameters affecting the properties of the hybrid interply composite: form and type of composite components and manufacturing process parameters as well as the conditioning and used testing settings. On the one hand, the broad assortment of the available fiber reinforcements and polymer matrices, as well as the manufacturing methods, enables realization of the desired composite properties. On the other hand, the used parameters should be considered during the evaluation of the resulting carbon/flax composite properties; i.e., an accurate comparison of different composites' properties is possible only if the above-mentioned factors are comparable. Consequently, prior to the evaluation of properties of the carbon/flax hybrid composites, the first sections of this review discuss the types and forms of the fibers and matrices as well as the manufacture methods.

\section{Materials}

The hybrid carbon/flax fiber-reinforced polymer composites represent predominantly textile composites consisting of carbon and flax fabric plies with various weave patterns. Both preimpregnated (prepregs) and conventional textiles are used to manufacture these hybrid composites. In general, the prepregs result in a better matrix infiltration quality and a higher fiber fraction in the resulting composites and, thus, offer higher mechanical properties. The summary of the reported reinforcement types used for the manufacture of carbon/flax hybrid composites is presented in Table 3. This summary shows that mostly reinforcements with unidirectionally (UD) aligned yarns and filaments like, e.g., UD fabric (also called UD mats or noncrimp) and UD prepregs are used for the fabrication of the hybrid composites. The UD-aligned reinforcing fibers possess a lower degree of a so-called "crimp," which is the ratio of a stretched yarn from the textile to the textile strap $[31,32]$. In general, the crimp in textiles made of the same yarn material increases in the following sequence: UD, twill, and plain. One of the main advantages of the lower crimp is the higher mechanical performance of the resulting composites [31]. Hence, as a rule, the UD fabrics made of the same yarn material and possessing the same textile density offer higher mechanical reinforcement than the corresponding woven textiles. An extensive information 
TABLE 1: Overview of the studies on carbon-/flax polymer composites.

\begin{tabular}{|c|c|}
\hline Year & Purpose and main results of the study \\
\hline 2012 & $\begin{array}{l}\text { The study investigates the influence of the introduction of a carbon fabric layer on the bending } \\
\text { and tensile properties of two different flax-epoxy composites including a thinner and a denser }\end{array}$ \\
\hline 2012 & $\begin{array}{c}\text { flax textile. The results show that depending on the textile density, the nonhybrid flax composites } \\
\text { offer either high bending properties or high tensile properties. The introduction of the } \\
\text { carbon fabrics improves significantly the mechanical performance. }\end{array}$ \\
\hline
\end{tabular}

This work explores the influence of carbon/flax fiber hybridisation on the tensile, flexural, and thermal properties as well as on the water absorption. The results demonstrate that in the case of the hybrid composites, the carbon fibers significantly improve the water absorption behaviour, thermal stability, and mechanical properties, whereas the flax fibers enhance the toughness properties.

The study aims to evaluate tensile and flexural properties as well as the hardness of a carbon/flax fiber-reinforced epoxy composite for its potential use as an orthopaedic long-bone fracture plate. The manufactured hybrid composite possesses sufficiently high tensile and high flexural properties. Furthermore, compared with the currently clinically used orthopaedic metal plates, the hybrid composite is closer to the human cortical bone, thus making it a potential candidate for use in the fixation of long-bone fracture.

The purpose of the study is to investigate the effect of the stacking sequence and hybridisation of carbon/flax fiber-reinforced epoxy on predicted and experimentally determined damping properties. The results show a good agreement between the modelled and the experimentally obtained damping coefficients. The stacking sequence plays an important role on the bending and damping properties.

This study on the influence of stacking sequences on the bending, tensile, and impact damage properties shows that it is possible to improve the bending properties or impact damage tolerance by adjusting the stacking sequence of carbon and flax textiles.

The article focuses on the comparison and identification of the dielectric properties and identification of the relaxation processes in flax composites and carbon-/flax-epoxy composites. The results show that the presence of two carbon fiber plies in the hybrid composite leads to two interfacial polarization effects and locally decreases the adhesion of flax fibers in the epoxy matrix.

This study investigates the effect of carbon/flax hybridisation with varying flax volume fractions on the tensile, flexural, impact, and vibration properties including comparison of modelling and experimental data. The work shows that compared with aluminium, the hybrid composites offer beneficial mechanical and damping properties. The micromechanical approach offers a viable tool for the modelling of mechanical properties.

The study focuses on the correlation of theoretical and experimental values of the elastic modulus and damping properties with the fiber composition in carbon-/flax-epoxy in longitudinal and flexural modes. The results show that in several cases, the stiffness-damping relationships in hybrid composites can be predicted for both modes using the rule of hybrid mixtures and the laminate theory. The work investigates the introduction of carbon fibers into a flax composite and the influence of the stacking sequence on tensile properties and water absorption/recovery behaviour. The results show that the introduction of carbon plies in certain stacking sequences acts as a barrier for the water and leads to a significant improvement of tensile properties.

The study is aimed at investigating the damage progression during impact loading and postimpact fatigue loading using infrared thermography. The results show that the analysis in the transmission mode enables easier detection of the delamination defect. 
TABLe 1: Continued.

\begin{tabular}{|c|c|c|}
\hline Year & Purpose and main results of the study & Reference \\
\hline 2018 & $\begin{array}{l}\text { The study describes use of the reclaimed carbon fibers in combination with flax fibers for the } \\
\text { manufacture of hybrid composites. The tensile and damping properties of the manufactured } \\
\text { composites offer a viable solution for applications where a compromise between reduced } \\
\text { mechanical properties and enhanced secondary properties, like, e.g., vibration and noise mitigation, } \\
\text { and cost reduction is needed. }\end{array}$ & {$[23]$} \\
\hline 2018 & $\begin{array}{l}\text { This work focuses on the effect of the stacking sequence and fiber orientation on the theoretical and } \\
\text { experimental damping properties of carbon-/flax-epoxy composites. Close agreement is } \\
\text { achieved between the predicted and experimentally obtained damping coefficients. Furthermore, } \\
\text { flax textiles play a significant role regarding the damping properties of the hybrid composite. }\end{array}$ & {$[24]$} \\
\hline 2018 & $\begin{array}{l}\text { The study investigates the effect of the stacking sequence on theoretical and experimental tensile } \\
\text { properties and damage mode of the hybrid carbon-/flax-epoxy composites. The theoretical and } \\
\text { experimental values demonstrate good agreement in hybrid composites possessing linear behaviour. } \\
\text { Moreover, the specific strength of these hybrid composites is higher than that of aluminium. }\end{array}$ & {$[25]$} \\
\hline 2018 & $\begin{array}{l}\text { The introduction of recycled short carbon fibers into a flax-epoxy composite leads to a significant } \\
\text { enhancement of the flexural properties. Furthermore, the bending strength of the hybrid composite } \\
\text { can be adjusted using random or layered distribution of the recycled carbon fibers within } \\
\text { the hybrid composite. }\end{array}$ & {$[26]$} \\
\hline 2019 & $\begin{array}{l}\text { The study analyzes the effect of the stacking sequence of carbon-/flax-epoxy composites on static } \\
\text { and fatigue tensile properties and shows that the modulus of these composites depends significantly } \\
\text { on the fiber ratio. }\end{array}$ & {$[27]$} \\
\hline
\end{tabular}

TABLE 2: Chronological summary of the studies on carbon/flax polymer composites.

\begin{tabular}{lcccc}
\hline 2012-2013 & 2015 & 2016 & 2017 & 2018 \\
\hline Mechanical properties & Damping properties & Mechanical properties & Mechanical properties & Mechanical properties \\
Modelling & Damping properties & Damage progression & Damping properties \\
& Modelling & Application-specific & Modelling \\
& & Dielectric properties & Water absorption & Use of recycled \\
& & carbon fibers & Improvement of fiber \\
& & compatibility & Use of a third fiber type \\
& & &
\end{tabular}

about the types as well as the advantages and disadvantages of various textiles and weave patterns for composite applications is described in the literature [31]. Besides the types of textiles mentioned above, two studies on carbon/flax composites report use of the hopsack-weaved flax fibers, which is basically a modified plain weave pattern. Finally, two studies report the use of short fibers. In the former study, the carbon fibers are recycled from pyrolysis [23], and in the latter one, the recycled carbon fibers from production waste are used, e.g., from trimming or from cured carbon composite products [26].

Although the information on volume fraction of the composite constituents is a standard approach used in order to define the density, porosity, and mechanical performance of the synthetic fiber composites, the use of this data in the case of the natural fiber composites is controversial. On the one hand, the calculation of fiber volume fraction requires the measurement of the natural fiber density and this is a challenging task. Firstly, the challenge arises due to the nonuniform geometry and morphology of the natural fibers. Secondly, the measured density values depend on the measuring method. As an example, the values achieved using Archimedes' principle and a helium pycnometer can differ by up to $12 \%$ [33]. As an example, the density values of flax available in the literature vary from $1.0 \mathrm{~g} / \mathrm{cm}^{3}$ [34] to $1.57 \mathrm{~g} / \mathrm{cm}^{3}$ [35]. Consequently, as shown in Table 3 , in the case of the hybrid carbon/flax composites, the fiber volume fraction is rarely provided. However, on the other hand, an equal fiber volume fraction is one of the main parameters enabling accurate comparison of the properties of the composites. Theoretically, the use of one flax fiber type and one density measurement approach during the study would result in a constant error, enabling comparison of the specimens within one study. However, since the porosity volume fraction and therefore the matrix volume fraction in the hybrid carbon/flax with different sequences may differ, it is still challenging to ensure accurate adjustment of fiber volume fraction and compare mechanical performance [19].

Furthermore, the use of different carbon fibers induces certain challenges when comparing different composites. As an example, besides the form of the fibers, i.e., type of the textile or length of the short fibers, the type of the used CF also 


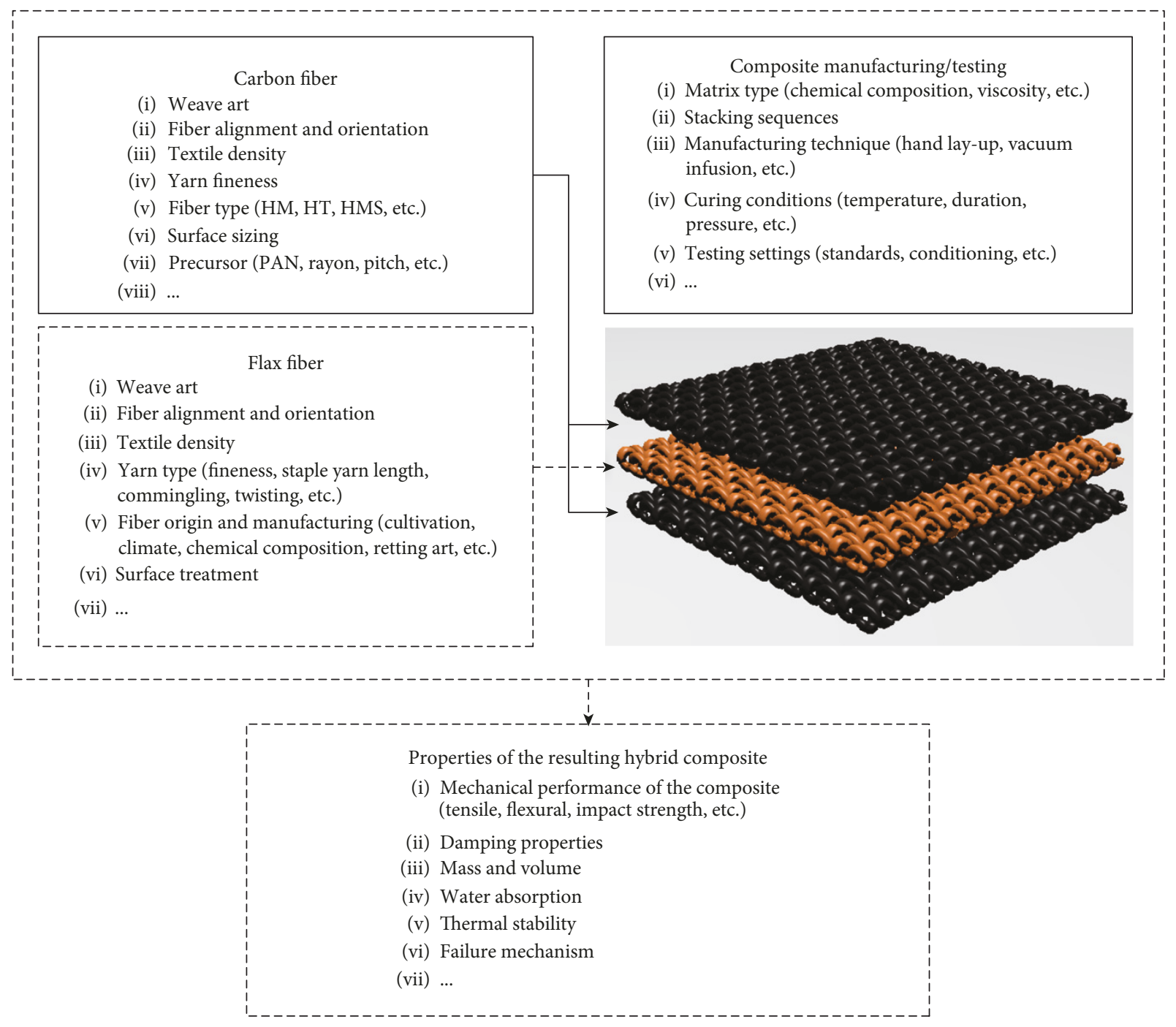

Figure 1: Factors affecting the properties of the resulting hybrid carbon/flax composites.

has a significant effect on the properties of the resulting hybrid composite. Basically, the carbon fibers can be classified according to the fiber structure and the degree of crystallite orientation as ultrahigh modulus (UHM), high modulus (HM), intermediate modulus (IM), high tensile strength, and isotropic. As an example, the UHM and HM carbon fibers are highly graphitized and offer a modulus higher than $500 \mathrm{GPa}$ or $300 \mathrm{GPa}$, respectively [36]. These types of carbon fibers and HT carbon fibers have a crystallite orientation mainly parallel to the fiber axis. In contrast, the isotropic fibers with lower modulus possess randomly oriented crystallites. These differences are achieved using different heattreatment temperatures of the carbon fibers. Further information on carbon fiber structure, manufacture, and properties is available in the literature [36]. The reviewed studies generally specify only the supplier and the trademark of the used carbon fibers without specifying the carbon fiber type. This should be considered during the evaluation of the hybrid carbon/flax composite properties.

Remarkably, according to Table 3, only epoxy resin is used as a polymer matrix in all of the reported studies. At the same time, two studies report the use of a partially biobased epoxy resin $[8,22]$. Consequently, further increasing the amount of a bio-based content in the carbon-/flax-epoxy composites contributes to environmental conservation.

Besides the fiber and the textile type used for the manufacture of a composite, the density of the used textile plays an important role. The textile density is directly linked to its thickness. Consequently, among other parameters, the textile density is a significant factor for the decision on the number of plies used for the manufacture of a composite specimen with a certain thickness. The required specimen thickness is generally predetermined by the testing standards. Furthermore, for the resulting composites, the textile density plays a significant role with regard to the fiber volume and mass fraction. In general, the higher fiber content leads to higher mechanical performance. However, if a critical fiber mass fraction is reached, i.e., there is not enough polymer matrix to infiltrate the fibers and hold them together, the mechanical performance starts to decrease [34]. At the same time, generally, the high porosity of natural fibers makes it difficult to produce composites with high fiber content [15]. 
TABLE 3: Overview of the components used for the manufacture of hybrid carbon/flax composites.

\begin{tabular}{|c|c|c|c|c|c|c|c|c|}
\hline $\mathrm{CF}$ & $\begin{array}{l}\rho_{\mathrm{CF}^{2}} \\
\left(\mathrm{~g} / \mathrm{m}^{2}\right)\end{array}$ & Content CF & FLA & $\begin{array}{l}\rho_{\mathrm{FLA}} \\
\left(\mathrm{g} / \mathrm{m}^{2}\right)\end{array}$ & Content FLA & $\begin{array}{c}\text { Content CF } \\
\text { \& FLA }\end{array}$ & Matrix & Reference \\
\hline Twill & 300 & $0-52$ vol. $\%$ & Twill & 350 & 0-39 vol.\% & - & EP & {$[14]$} \\
\hline Twill & 300 & $0-55$ vol. $\%$ & UD fabric & 200 & $0-32$ vol. $\%$ & - & EP & {$[24]$} \\
\hline Twill 2/2 & 200 & 50 vol. $\%$ & Plain & 235 & NS & $32-40.5$ vol. $\%$ & $\mathrm{EP}$ & [19] \\
\hline Twill 2/2 & 240 & $0-58$ vol. $\%$ & $\begin{array}{l}\text { Hopsack 4/4 } \\
\text { Twill } 2 / 2\end{array}$ & $\begin{array}{l}500 \\
420\end{array}$ & NS & - & $\mathrm{EP}$ & {$[18]$} \\
\hline UD prepreg & 476 & $\begin{array}{l}37 \text { wt.\% } \\
\text { (prepreg) }\end{array}$ & $\begin{array}{l}\text { Twill } 2 / 2 \text { prepreg } \\
\text { Ribs } 4 / 4 \text { prepreg }\end{array}$ & $\begin{array}{l}315 \\
190\end{array}$ & $\begin{array}{l}55 \text { wt.\% } \\
\text { (prepreg) }\end{array}$ & - & $\mathrm{EP}$ & {$[13]$} \\
\hline UD prepreg & 300 & NS & UD prepreg & 180 & NS & $56-62$ vol. $\%$ & $\mathrm{EP}$ & {$[15]$} \\
\hline UD prepreg & NS & NS & Quasi-UD-prepreg & 180 & NS & 50 vol. $\%$ & $\mathrm{EP}$ & {$[16]$} \\
\hline UD prepreg & NS & $\begin{array}{l}57 \text { vol.\% } \\
\text { (prepreg) }\end{array}$ & UD prepreg & NS & $\begin{array}{c}\text { 58-60 vol.\% } \\
\text { (prepreg) }\end{array}$ & NS & $\mathrm{EP}$ & [9] \\
\hline UD fabric & 320 & NS & $\begin{array}{l}\text { Twill } \\
\text { Plain }\end{array}$ & $\begin{array}{l}220 \\
150\end{array}$ & NS & $49-51.5$ vol. $\%$ & $\mathrm{EP}$ & {$[12]$} \\
\hline UD fabric & 448 & 0-61 vol.\% & UD fabric & 275 & $0-38$ vol. $\%$ & $38-61$ vol. $\%$ & $\mathrm{EP}$ & {$[17]$} \\
\hline UD fabric & NS & & UD fabric & NS & & 50 vol. $\%^{1}$ & Bio-EP & {$[8]$} \\
\hline Plain & 197 & 0-66 vol.\% & Hopsack 4/4 & 500 & 0-29 vol.\% & $29-66$ vol.\% & $\mathrm{EP}$ & {$[25]$} \\
\hline Plain & 200 & 12 wt. $\%$ & UD fabric & 380 & 27 wt.\% & 53 wt. $\%^{2}$ & EP & [21] \\
\hline Plain & 200 & ca. $10-20$ wt. $\%$ & Plain & 435 & ca. $27-31$ wt. $\%$ & ca. $27-51$ wt. $\%$ & Bio-EP & {$[22]$} \\
\hline Short rCF (pyrolysis) & - & $100-0$ wt. $\%^{3}$ & Short fibers & - & $0-75$ wt. $\%$ & 35 vol. $\%$ & EP & [23] \\
\hline $\begin{array}{l}\text { Short rCF } \\
\text { (dry fiber cut-off) }\end{array}$ & - & $30-0$ vol. $\%$ & Staple fibers & & 0-30 vol.\% & 30 vol. $\%$ & EP & [26] \\
\hline Woven (NS) & 480 & NS & UD mat & NS & NS & NS & $\mathrm{EP}$ & {$[20]$} \\
\hline
\end{tabular}

Note: CF: carbon fibers; FLA: flax fibers; EP: epoxy; $\rho$ : density; rCF: recycled carbon fibers; NS: not stated. ${ }^{1}$ Planned fiber volume fraction. ${ }^{2}$ Third fiber type used: 14 wt.\% basalt fibers. ${ }^{3}$ Relative indication compared to other specimens.

The reported density of both the carbon and flax fiber textiles lies in the same region (Table 3). This data includes the density values of the textiles and prepregs. The latter group already contains a certain amount of epoxy resin. The assessment of this data shows that since all of the combinations offer certain benefits, there is no certain tendency regarding the densities of the textiles hybridised in one composite. As an example, a carbon/flax composite with a thin plainweaved carbon textile $\left(197 \mathrm{~g} / \mathrm{m}^{2}\right)$ can be combined with a thick hopsack-weaved flax textile $\left(500 \mathrm{~g} / \mathrm{m}^{2}\right)$ [25], or vice versa, a thick carbon prepreg $\left(476 \mathrm{~g} / \mathrm{m}^{2}\right)$ is used together with a thin flax prepreg $\left(190 \mathrm{~g} / \mathrm{m}^{2}\right)$ [13]. In order to make a more precise statement regarding the beneficial type and density of carbon and flax reinforcements for the manufacture of the hybrid composites, the individual cases should be analyzed with regard to the overall number of the textile plies used, the stacking sequences, and the fiber content. However, due to the large amount of this data, the review of this information goes beyond the scope of this study.

\section{Composite Manufacture}

Typically, conventional techniques, which are already established for the fabrication of nonhybrid thermoset composites, are also used for the manufacture of hybrid carbon-/flax-epoxy composites. The summary of these techniques and the reported procedure details are presented in Table 4. Particularly, direct pressure moulding (or hot- pressing) or a vacuum bagging in combination with autoclave is used for the prepreg processing, and the vacuum bagging technique as a single step (vacuum infusion) or hand lay-up in combination with pressure moulding is used for the processing of fiber textiles. Specially developed techniques are used for the manufacture of carbon/flax short fiber-epoxy composites. These methods are presented in Table 4, including the fiber preparation steps $[23,26]$. The basic information regarding the techniques used for the fiber-reinforced composite manufacture is described extensively in the literature $[29,34]$.

Although the used techniques can be easily grouped into several manufacturing methods, some of the procedure parameters like, e.g., predrying conditions of flax fibers before the composite manufacturing or curing cycle of the carbon/flax composite differ from each other significantly.

Hygroscopic behaviour of natural fibers is one of the sources leading to a poor fiber-matrix adhesion in natural fiber polymer composites and, therefore, lower mechanical performance and short durability of the resulting composite product. Consequently, the predrying of natural fibers before the composite manufacturing is an important step to ensure high quality of the resulting composites. However, there is neither a standard procedure for the predrying of the natural fibers nor a literature describing systematically the effect of the predrying of natural fibers on composite properties. Therefore, numerous research groups carrying out research on natural fiber-reinforced composites develop and use their 
TABLE 4: Overview of the reported techniques used to manufacture carbon-/flax-epoxy composites.

\begin{tabular}{|c|c|c|}
\hline Composite manufacture & Procedure & Reference \\
\hline & $\begin{array}{l}\text { (1) Predrying of flax fibers for at } 110^{\circ} \mathrm{C} / 1 \mathrm{~h} \\
\text { (2) Impregnation of textiles with resin } \\
\text { (3) Curing at } 20^{\circ} \mathrm{C} / 0.5 \text { bar, } 7 \mathrm{~h}\end{array}$ & {$[24]$} \\
\hline \multirow{5}{*}{ Hand lay-up and pressure moulding } & $\begin{array}{l}\text { (1) Impregnation of textiles one by one with resin } \\
\text { (2) Curing at } 35^{\circ} \mathrm{C} / 3 \mathrm{~h} / 5 \mathrm{bar}\end{array}$ & {$[14]$} \\
\hline & $\begin{array}{l}\text { (1) Impregnation of textiles with resin } \\
\text { (2) Curing in } 2 \text { steps: } 200 \mathrm{kPa} / 8 \mathrm{~h} \text { and } 80^{\circ} \mathrm{C} / 1 \mathrm{~h}\end{array}$ & {$[8]$} \\
\hline & $\begin{array}{l}\text { (1) Impregnation of textiles with resin } \\
\text { (2) Curing in } 2 \text { steps: } 10 \text { bar/RT, } 24 \mathrm{~h}\end{array}$ & {$[20]$} \\
\hline & $\begin{array}{l}\text { (1) Impregnation of textiles with resin } \\
\text { (2) Curing in } 3 \text { steps: at RT/ } 0.9 \text { bar } / 24 \mathrm{~h} \text { and } 80^{\circ} \mathrm{C} / 30 \mathrm{~min} \text { and } 130^{\circ} \mathrm{C} / 60 \mathrm{~min}\end{array}$ & {$[19]$} \\
\hline & $\begin{array}{l}\text { (1) Impregnation of textiles with resin } \\
\text { (2) Precure of separate textile at } 105^{\circ} \mathrm{C} / 10 \mathrm{~min} \\
\text { (3) Vacuum bagging for at } \mathrm{RT} / 1 \mathrm{~h} \\
\text { (4) Curing in } 4 \text { steps: } 80^{\circ} \mathrm{C} / 10 \mathrm{~min} / 6 \mathrm{MPa}, 110^{\circ} \mathrm{C} / 30 \mathrm{~min} / 9 \mathrm{MPa}, 110^{\circ} \mathrm{C} / 24 \mathrm{~h} \text {, and } 150^{\circ} \mathrm{C} / 5 \mathrm{~h}\end{array}$ & {$[18]$} \\
\hline \multirow{3}{*}{ Pressure moulding } & (1) Pressure moulding at $\max .130^{\circ} \mathrm{C} / 0.5 \mathrm{MPa} / 45 \mathrm{~min}$ & {$[13]$} \\
\hline & (1) Pressure moulding at $150^{\circ} \mathrm{C} / 500 \mathrm{kPa} / 60 \mathrm{~min}$ & [9] \\
\hline & (1) NS & [16] \\
\hline \multirow{5}{*}{ Vacuum bagging } & $\begin{array}{l}\text { (1) Vacuum bagging } \\
\text { (2) Curing in } 2 \text { steps: at } \mathrm{RT} / 24 \mathrm{~h} \text { and at } 60^{\circ} \mathrm{C} / 8 \mathrm{~h}\end{array}$ & {$[12]$} \\
\hline & $\begin{array}{l}\text { (1) Predrying of flax at } 80^{\circ} \mathrm{C} / 24 \mathrm{~h} \\
\text { (2) Vacuum infusion including } 30 \text { min debulk at } 1 \mathrm{~atm} \\
\text { (3) Curing in } 2 \text { steps: at RT/24h and at } 80^{\circ} \mathrm{C} / 24 \mathrm{~h}\end{array}$ & {$[17]$} \\
\hline & $\begin{array}{l}\text { (1) Predrying of flax at } 90^{\circ} \mathrm{C} / 3 \mathrm{~h} \\
\text { (2) Vacuum infusion } \\
\text { (3) Curing in } 2 \text { steps: at } 25^{\circ} \mathrm{C} / 24 \mathrm{~h} \text { and at } 80^{\circ} \mathrm{C} / 16 \mathrm{~h}\end{array}$ & {$[25]$} \\
\hline & $\begin{array}{l}\text { (1) Predrying of flax at } 60^{\circ} \mathrm{C} / 15 \mathrm{~min} \\
\text { (2) Vacuum infusion } \\
\text { (3) Curing in } 2 \text { steps: } 28^{\circ} \mathrm{C} / 0.88 \text { bar and at } 80^{\circ} \mathrm{C} / 14 \mathrm{~h}\end{array}$ & {$[21]$} \\
\hline & $\begin{array}{l}\text { (1) Predrying of flax fibers at } 80^{\circ} \mathrm{C} / 24 \mathrm{~h} \\
\text { (2) Vacuum infusion } \\
\text { (3) Curing for } 30 \mathrm{~min} \text { at } 80^{\circ} \mathrm{C}\end{array}$ & {$[22]$} \\
\hline Vacuum bagging and autoclave & (1) Curing under pressure in autoclave at $120^{\circ} \mathrm{C}$ & {$[15]$} \\
\hline Impregnation and autoclave & $\begin{array}{l}\text { (1) Suspension of short fibers in water } \\
\text { (2) Alignment of fibers using sudden change of momentum of the fiber-water suspension } \\
\text { (3) Drying and impregnation of fibers with resin } \\
\text { (4) Curing in autoclave at } 135^{\circ} \mathrm{C} / 6 \mathrm{bar} / 135 \mathrm{~min}\end{array}$ & {$[23]$} \\
\hline Single line infusion & $\begin{array}{l}\text { (1) Opening of fibers via process based on gas jet mixer } \\
\text { (2) Mixing of fibers at a certain mass ratio } \\
\text { (3) Carding process including compression of fibers } \\
\text { (4) Line infusion of fibers via liquid resin infusion } \\
\text { (5) Curing in } 2 \text { steps: at } 85^{\circ} \mathrm{C} / 120 \mathrm{~min} \text { and } 100^{\circ} \mathrm{C} / 60 \mathrm{~min} \text { in oven }\end{array}$ & {$[26]$} \\
\hline
\end{tabular}

Note: RT: room temperature; NS: not stated.

own internal standards, which may significantly differ from one another. The review of the reported studies on the carbon/flax composites shows that in the cases where the predrying of flax takes place, the conditions vary from drying at $60^{\circ} \mathrm{C}$ for $15 \mathrm{~min}$ [21] to drying at $110^{\circ} \mathrm{C}$ for $1 \mathrm{~h} \mathrm{[24]} \mathrm{or} \mathrm{at}$ $80^{\circ} \mathrm{C}$ for $24 \mathrm{~h} \mathrm{[22]} \mathrm{or} \mathrm{at} 90^{\circ} \mathrm{C}$ for $3 \mathrm{~h} \mathrm{[25].} \mathrm{Certainly,} \mathrm{these} \mathrm{dif-}$ ferences have a certain influence on the properties of the resulting composites, because drying affects the mechanical properties of the natural fibers themselves. As an example, the tensile strength of the flax fibers after drying at $105^{\circ} \mathrm{C}$ for $14 \mathrm{~h}$ reduces on average by $44 \%$ and the failure strain by
$39 \%$ [37]. However, with regard to the existing information, it is difficult to evaluate the influence of the predrying of flax fibers on the properties of the carbon/flax composites.

The curing cycle is dependent on the epoxy system used for the composite manufacture. At the same time, generally, for one epoxy system, there are several curing cycles available. The number of the curing steps as well as the used temperatures define the physical and mechanical properties of the epoxy resin [38] and thus of the resulting composite. Frequently, there are two steps used for the curing of epoxy composites. During the first longer step, taking place at lower 
temperature, the cross-linking between the resin and the hardener starts and progresses, so that the epoxy matrix becomes solid. During the second curing step (or postcure), the composite is subjected to a higher temperature for a shorter time, so that the cross-linking between the resin and the hardener is completed and the glass transition temperature $\left(T_{\mathrm{g}}\right)$ of the cured epoxy matrix is increased. The higher $T_{\mathrm{g}}$ broadens the operating temperature of the resulting composite. Further detailed information on the curing and postcuring of epoxy is broadly available in the literature [38]. The overview presented in Table 4 shows that in the case of prepregs, the curing is generally realized in one step via pressure moulding at $130^{\circ} \mathrm{C}$ or $150^{\circ} \mathrm{C}$ for 45 or $60 \mathrm{~min}$ $[9,13]$ or vacuum bagging and curing in autoclave at $120^{\circ} \mathrm{C}$ [15]. In the case of hand lay-up combined with pressure moulding, the curing varies quite considerably from onestep curing at $20^{\circ} \mathrm{C}$ for at least $7 \mathrm{~h}$ to curing in 4 steps, with a temperature range from $80^{\circ} \mathrm{C}$ to $150^{\circ} \mathrm{C}$, which takes around $30 \mathrm{~h}$. The curing during a single-step vacuum bagging, which is also known as a vacuum infusion process, commonly takes place in 2 steps with a maximum temperature of $90^{\circ} \mathrm{C}$. In the case of short fiber carbon/flax composites, at the beginning of the composite manufacture, the fibers are in the form of prepreg with mixed aligned carbon and flax fibers preimpregnated with epoxy resin [23] or mixed and compressed carbon and flax fibers [26]. Consequently, in the former case, the short fibers are processed similarly as typical prepregs via curing in autoclave. In the latter case, using a so-called single line infusion method, the same line is used for the vacuum generation and for the resin infusion [26].

To sum up, conventional technical equipment is used for the manufacture of carbon-/flax-epoxy composites. Due to the adjustment of the selected manufacturing technique parameters and the used epoxy resin, it is potentially possible to control the duration of the fabrication process and the properties of the resulting hybrid composites.

\section{Tensile Properties}

The capacity of a composite material to resist the load tending to elongate it, namely, the tensile property of the composite, is one of the key material characteristics. Review of the reported studies on carbon/flax composites shows that the tensile properties and the corresponding failure mode of these hybrid composites are mainly dependent on the carbon fiber content, stacking sequence, and weave art of the used flax textiles.

The strength and stiffness of hybrid composites increases with the increase of carbon fiber content. This tendency seems to be independent, whether carbon fiber textile $[13,17,18]$ or short recycled carbon fibers [23] are used. As example, the replacement of one flax ply with a carbon ply in a composite with 6 plies leads to increase of the tensile modulus of about $262.0 \%$ and tensile strength of $266.4 \%$ [12]. However, the increase of carbon fiber content in textile carbon/flax composites leads to the decrease of strain to failure [13]. At the same time, in the case of short fibers, the strain to failure is nearly independent of the carbon content [23].
The stacking sequence of the carbon-/flax-epoxy composites also significantly affects the values of tensile strength and modulus, although this is not expected with regard to the classical laminate theory. According to the classical laminate theory, for symmetric balanced laminate layers of different nature, the tensile properties are not dependent on the stacking sequence [39]. Nevertheless, it is important to consider that this theory is based on the following assumptions:

(1) The laminate is composed of perfectly bonded plies

(2) The normal to the midplane of the laminate remains straight and normal to the deformed midplane after deformation

Consequently, it is assumed that the interlaminar transversal shear stress between the laminate plies is negligible.

(3) The normal to the midplane of the laminate does not change the length (constant thickness)

However, the fiber-matrix adhesion at the carbon-epoxy and flax-epoxy interphase is different. Furthermore, the both fiber types differ in surface morphology; thus, the bonding between the plies can vary. In addition, real systems can possess a certain amount of porosity in the composite structure. Moreover, polymer composite structures can undergo deformation depending on the changes in temperature or moisture content, since the moisture absorption by matrices can lead to the swelling of the structure [39]. Consequently, under real conditions, the tensile properties of hybrid carbon/flax composites can show some deviation with regard to the stacking sequence.

Particularly, the tensile modulus can differ by $23 \%$ and of strength by around $10 \%$ depending on the stacking sequence [19]. According to the authors, the improvement of the tensile modulus is mainly induced by the nature of the outer ply of the hybrid composite; i.e., carbon fibers at the outer layer lead to higher tensile properties. Furthermore, it is reported that the alternation of flax and carbon plies inside the hybrid composite also promotes this effect, but not significantly.

Furthermore, depending on the stacking sequence of the composite structure, the carbon/flax composite can show a more brittle or a more ductile behaviour. The hybrid composite behaviour under tensile loading tends to the brittle behaviour of the carbon composite, if carbon is the outer ply, or ductile towards the flax composite, if flax is the outer ply [19]. However, the tensile testing monitored via Digital Image Correlation shows that both hybrid composites with either carbon or flax outer plies possess a similar damage development with regard to the cracks and delamination. At the same time, in the stacking sequence carbon-flax-carbon, the failure starts earlier than in flax-carbon-flax, representing outer-inner-outer plies, respectively [15]. At the same time, the introduction of basalt fibers inside the carbon/flax composite with outer carbon plies and analysis of the tensile properties with regard to the changed stacking sequence inside the hybrid composite does not show any 


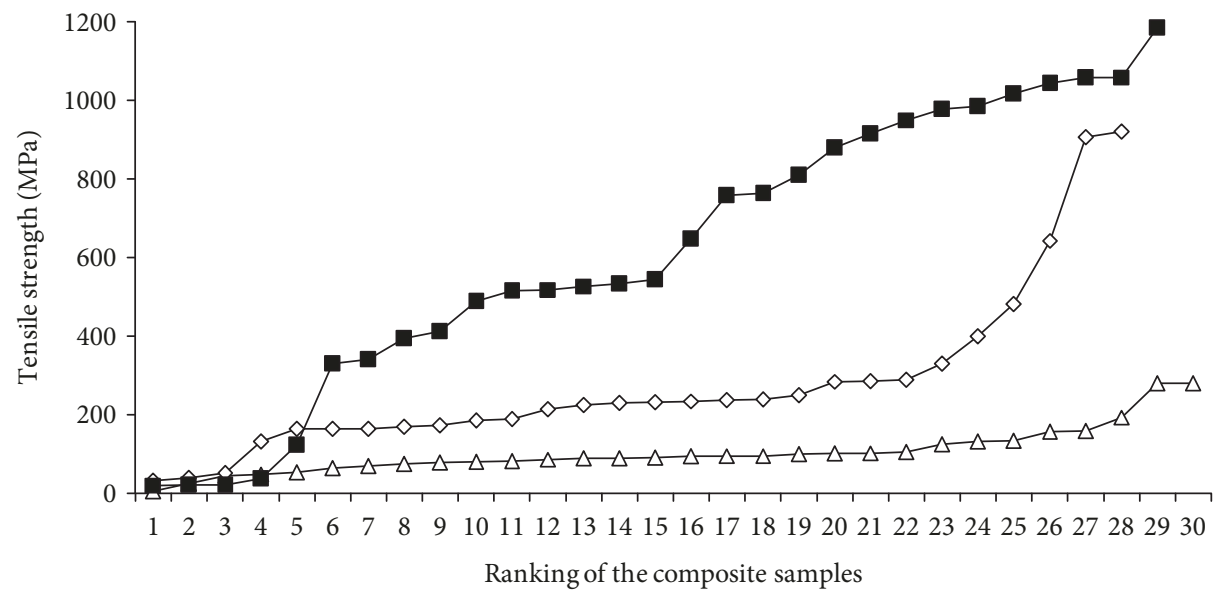

$\triangleleft$ Natural fiber composites
$\checkmark-$ Hybrid fiber composites
$\neg$ Carbon fiber composites

Figure 2: Tensile strength of carbon-/flax-epoxy composites and nonhybrid carbon- and flax-epoxy composites $[9,12,13,17,19,21,23,25$, $26,40-51]$.

significant change [21]. Consequently, in the case of the varied stacking sequence, the outer fiber type plays the most important role.

Analysis of the stress-strain curves shows that the weave art of the flax plies affects both mean values of the tensile strength and modulus as well as the failure mode. Particularly, hybrid composites with a plain-weaved flax $\left(150 \mathrm{~g} / \mathrm{m}^{2}\right)$ result in a predominantly tensile failure of UD carbon plies $\left(320 \mathrm{~g} / \mathrm{m}^{2}\right)$ followed by delamination between carbon and flax plies [12]. The same behaviour is observed in the case of the varied stacking sequences and fractions of UD carbon $\left(448 \mathrm{~g} / \mathrm{m}^{2}\right)$ and UD flax $\left(275 \mathrm{~g} / \mathrm{m}^{2}\right)$ composites, where this delamination ends with the rupture of flax plies [17]. According to the literature, this behaviour is caused by lower strain of failure of carbon fibers compared to flax and the twist of the yarns in flax fabric [17]. On the contrary, the use of twill-weaved flax $\left(220 \mathrm{~g} / \mathrm{m}^{2}\right)$ textiles and UD carbon $\left(320 \mathrm{~g} / \mathrm{m}^{2}\right)$ results in a brittle failure of the hybrid composites without delamination [12]. This brittle failure without the intermediate delamination step results in lower mean values of tensile properties [12]. The same brittle behaviour is observed in the case of 16 plies of UD flax and 2 plies of UD carbon prepregs [9]. Additionally, the introduction of carbon fibers into flax composites with originally different weave patterns and different tensile values can overturn the order of the mean tensile values. Particularly, the introduction of the same carbon ply into a plain-weaved flax composite, with lower tensile properties, and a twill-weaved flax composite, with higher tensile properties, results in hybrid carbon/plain flax composites with higher tensile properties and a hybrid carbon/twill flax composite with lower tensile properties [12]. This is also perhaps related to the differences in failure modes.

Overall values of tensile strength and modulus of the reported hybrid carbon-/flax-epoxy composites in comparison with nonhybrid carbon- or flax-epoxy composites are presented in Figures 2 and 3, respectively. The data in Figures 2 and 3 represent an overall ranking of the reported values independently of the types and forms of the used materials and manufacturing methods. Furthermore, these data also includes the values of the residual tensile testing, e.g., after the impact loading [15]. Only few reports on carbon-/flax-epoxy composites analyzed tensile properties in comparison with the corresponding nonhybrid systems. Consequently, in order to provide an accurate evaluation with respect to the properties of the nonhybrid composites, some of the data on the nonhybrid carbon- and flax-epoxy composites are used from other studies, where similar materials and manufacturing techniques are used. The overview of these nonhybrid composites and the corresponding manufacturing techniques are described in Tables 5 and 6.

Both Figures 2 and 3 show that using carbon/hybrid composites, it is possible to reach the tensile properties of the carbon composites. The highest tensile strength value of the hybrid composites in Figure 2, namely, 921.50 MPa, is reached using 8 plies of UD flax prepreg with the density of $180 \mathrm{~g} / \mathrm{m}^{2}$ as outer layers and 10 plies of UD carbon prepregs with the density of $300 \mathrm{~g} / \mathrm{m}^{2}$ inside the hybrid composite [15]. The second highest value, namely, 907.15 MPa, is the residual tensile of the same hybrid composite after impact loading with $10 \mathrm{~J}$. The lowest values refer to the systems with nontextile short flax and recycled carbon fibers [23].

Similarly, as in the case of tensile strength, the ranking of the tensile modulus values represented in Figure 3 shows that the hybridisation of high-performance carbon fibers with flax fibers results in a significant improvement of the tensile modulus in comparison with nonhybrid flax or sometimes also carbon-epoxy composites. The specimens, which have the highest residual tensile strength, also result in the highest tensile modulus, namely, $63.25 \mathrm{GPa}$ [15]. As expected, the lowest values are realized using short fiber hybrid composites [23, 26]. 


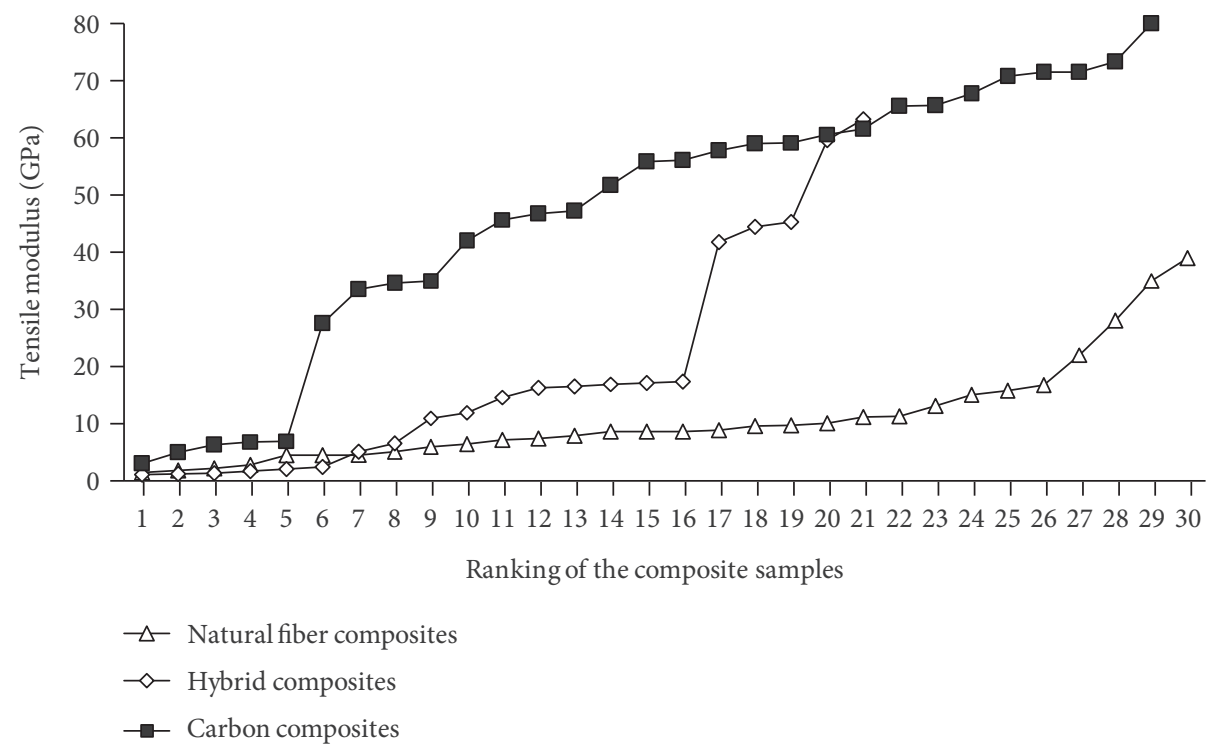

FIGURE 3: Tensile modulus of carbon-/flax-epoxy and nonhybrid carbon- or flax-epoxy composites $[9,12,13,17,19,21,23,25,26,40-51]$.

TABLE 5: Materials used for the manufacture of nonhybrid composites (Figures 2-5).

\begin{tabular}{|c|c|c|c|}
\hline & Density $\left(\mathrm{g} / \mathrm{m}^{2}\right)$ & Matrix & References \\
\hline \multicolumn{4}{|l|}{ Carbon fiber-epoxy composites } \\
\hline Plain & 200 & $\mathrm{EP}$ & {$[42]$} \\
\hline Satin $(3 K)$ & NS & $\mathrm{EP}$ & {$[52]$} \\
\hline UD fabric & 180 & $\begin{array}{l}\text { EP } 1 \\
\text { EP } 2 \\
\text { EP } 3\end{array}$ & {$[40]$} \\
\hline $\begin{array}{l}\text { Plain prepreg } \\
\text { Eight harness satin }\end{array}$ & NS & $\begin{array}{l}\text { EP } 1 \\
\text { EP } 2\end{array}$ & {$[41]$} \\
\hline \multicolumn{4}{|l|}{ Flax fiber-epoxy composites } \\
\hline Woven (NS) & 280 & $\mathrm{EP}$ & {$[43]$} \\
\hline $\begin{array}{l}\text { UD fabric } \\
\text { Nonwoven }\end{array}$ & $\begin{array}{l}\text { NS } \\
\text { NS }\end{array}$ & $\begin{array}{l}\mathrm{EP} \\
\mathrm{EP}\end{array}$ & {$[44]$} \\
\hline $\begin{array}{l}\text { UD fabric } \\
\text { UD mat }\end{array}$ & $\begin{array}{l}\text { NS } \\
\text { NS }\end{array}$ & $\begin{array}{l}\mathrm{EP} \\
\mathrm{EP}\end{array}$ & {$[47]$} \\
\hline Needle-punched nonwoven & 310 & $\mathrm{EP}$ & {$[48]$} \\
\hline $\begin{array}{l}\text { Twill } 2 / 2 \text { prepreg } \\
\text { Twill } 2 / 2 \text { prepreg }\end{array}$ & $\begin{array}{l}196 \\
543\end{array}$ & $\mathrm{EP}$ & {$[54]$} \\
\hline UD fabric & 150 & $\mathrm{EP}$ & [49] \\
\hline UD noncrimp & NS & $\mathrm{EP}$ & {$[46]$} \\
\hline Quasi-UD-prepreg & 170 & EP & {$[50]$} \\
\hline Fibers & - & EP & {$[45]$} \\
\hline Woven fabrics (NS) & 550 & $\mathrm{EP}$ & {$[55]$} \\
\hline Fibers & - & $\mathrm{EP}$ & {$[53]$} \\
\hline $\begin{array}{l}\text { Twill } 2 / 2 \text { prepreg } \\
\text { Twill } 2 / 2 \text { prepreg }\end{array}$ & $\begin{array}{l}200 \\
420\end{array}$ & $\begin{array}{l}\text { EP } 1 \\
\text { EP } 2\end{array}$ & {$[51]$} \\
\hline
\end{tabular}

Note: NS: not stated.

\section{Bending Properties}

The bending properties of carbon-/flax-epoxy composites show dependency on the fiber content, weave art, and stack- ing sequence. Furthermore, the stacking sequence also affects the residual flexural properties after impact loading.

Similarly as in the case of tensile properties, the increase of flax fiber content in hybrid composites leads to the decrease of the flexural modulus and the ultimate flexural strength $[12,13,17]$. However, due to the hybridisation of carbon with flax, the elongation of the break in comparison with nonhybrid carbon-epoxy composites is improved [13].

Contrary to the tensile properties, the introduction of a carbon ply to a flax composite has a greater beneficial effect for flax composites, which already have higher bending values $[12,13]$. Particularly, introduction of a carbon ply to a flax (plain) composite with bending strength of 76.42 $\mathrm{MPa}$ results in 160.42 $\mathrm{MPa}$, whereas introduction of a carbon ply to a flax (twill) composite with $61.05 \mathrm{MPa}$ results in $85.00 \mathrm{MPa}$ [12].

Bending properties are significantly influenced by the stacking sequence of the hybrid composites. The reason for this is that during the bending, the testing specimen is subjected to different loads at the top and bottom and in the middle, namely, compression, tension, and shear loading. As expected from the sandwich theory, the composites with outer carbon plies and inner flax plies result in significantly higher flexural properties than vice versa $[15,17,22]$. This tendency is valid also for hybrid composites with short recycled carbon fibers [26]. As an example, the use of carbon plies at outer layers results in a flexural strength and modulus of $641.11 \mathrm{MPa}$ and $74.76 \mathrm{GPa}$, respectively, whereas the use of the same carbon ply at inner layers results in $534.90 \mathrm{MPa}$ and $36.22 \mathrm{GPa}$, respectively [15]. However, the postimpact residual flexural strength of these two stacking sequences with $20 \mathrm{~J}$ or higher are overturned [15]. As an example, after the impact loading, the bending strength of the abovementioned stacking sequence carbon-flax-carbon results in 287.54 $\mathrm{MPa}$ and the hybrid composite flax-carbon-flax in $339.56 \mathrm{MPa}$. At the same time, the bending modulus of the stacking sequence with outer carbon layers is higher, i.e., 
TABLE 6: Methods used for the manufacture of nonhybrid composites (Figures 2-5).

\begin{tabular}{|c|c|c|}
\hline & Procedure & Reference \\
\hline \multicolumn{3}{|l|}{ Carbon fiber epoxy composites } \\
\hline Hand lay-up and compression moulding & $\begin{array}{l}\text { (1) Impregnation of textiles with epoxy resin } \\
\text { (2) Compression moulding } 120^{\circ} \mathrm{C} / 4 \mathrm{~h} / 130 \mathrm{kN}\end{array}$ & {$[52]$} \\
\hline $\begin{array}{l}\text { Hand lay-up and vacuum bagging in } \\
\text { autoclave }\end{array}$ & $\begin{array}{l}\text { (1) Impregnation of textiles with epoxy resin } \\
\text { (2) Autoclave curing at } 60^{\circ} \mathrm{C} / 12 \mathrm{~h}\end{array}$ & {$[40]$} \\
\hline Autoclave & $\begin{array}{l}\text { (1) Autoclave curing at } 177^{\circ} \mathrm{C} / 120 \mathrm{~min} / 0.70 \mathrm{MPa} \text { or } 121^{\circ} \mathrm{C} / 90 \mathrm{~min} \text { depending on the } \\
\text { epoxy type }\end{array}$ & {$[41]$} \\
\hline Hand lay-up & $\begin{array}{l}\text { (1) Impregnation of textiles with resin } \\
\text { (2) Curing in } 2 \text { steps: } \mathrm{RT} / 24 \mathrm{~h}, 75^{\circ} \mathrm{C} \text { in a stove }\end{array}$ & {$[42]$} \\
\hline \multicolumn{3}{|l|}{ Flax fiber epoxy composites } \\
\hline Hand lay-up and vacuum bagging & $\begin{array}{l}\text { (1) Impregnation of textiles with resin } \\
\text { (2) Conditioning at RT for } 2 \text { weeks }\end{array}$ & {$[43]$} \\
\hline Autoclave & $\begin{array}{l}\text { (1) Impregnation of textiles with resin } \\
\text { (2) Moulding under vacuum at } 125^{\circ} \mathrm{C} / 3 \text { bar }\end{array}$ & {$[44]$} \\
\hline Film stacking and autoclave & $\begin{array}{l}\text { (1) UD alignment of fibers } \\
\text { (2) B-staged epoxy sheets are put on the top, between, and under the textile layers } \\
\text { (3) Curing in autoclave at } 125^{\circ} \mathrm{C} / 3 \mathrm{bar} / 1 \mathrm{~h}\end{array}$ & {$[53]$} \\
\hline Film stacking and autoclave & $\begin{array}{l}\text { (1) Pre-impregnation of fibers } \\
\text { (2) Film stacking using B-staged epoxy sheets } \\
\text { (3) Curing in autoclave at } 125^{\circ} \mathrm{C} / 3 \text { bar } / 1 \mathrm{~h}\end{array}$ & {$[45]$} \\
\hline Hand lay-up & Not stated & {$[46]$} \\
\hline Autoclave & (1) Curing in autoclave under varied parameters & {$[54]$} \\
\hline RTM & $\begin{array}{l}\text { (1) Pressure } 1 \text { or } 2 \text { bars depending on the fiber content. } \\
\text { Injection at } 50^{\circ} \mathrm{C} \text {, curing at } 80^{\circ} \mathrm{C} / 8 \mathrm{~h}\end{array}$ & {$[47]$} \\
\hline Hand lay-up & $\begin{array}{l}\text { (1) Resin impregnation of mats } \\
\text { (2) Curing in a mould at } 80^{\circ} \mathrm{C} / 1 \mathrm{~h}\end{array}$ & {$[48]$} \\
\hline Hand lay-up and compression moulding & $\begin{array}{l}\text { (1) Resin impregnation of fabrics } \\
\text { (2) Compression moulding at } 120^{\circ} \mathrm{C} / 15 \mathrm{~min} / 2.5 \text { bar and at } 150^{\circ} \mathrm{C} / 2 \mathrm{~h} / 5 \mathrm{bar}\end{array}$ & [49] \\
\hline Vacuum bagging and autoclave & (1) Curing at $130^{\circ} \mathrm{C} / 4$ bar & {$[50]$} \\
\hline Hand lay-up and vacuum bagging & $\begin{array}{l}\text { (1) Resin impregnation } \\
\text { (2) Vacuum bagging } \\
\text { (3) Curing in } 2 \text { steps: } \mathrm{RT} / 24 \mathrm{~h} \text {, at } 65^{\circ} \mathrm{C} / 7 \mathrm{~h}\end{array}$ & [55] \\
\hline Vacuum bagging and autoclave & (1) Curing at $120^{\circ} \mathrm{C} / 60 \mathrm{~min} / 0.62 \mathrm{MPa}$ & {$[51]$} \\
\hline
\end{tabular}

Note: RT: room temperature; NS: not stated.

64.21 GPa compared to $33.87 \mathrm{GPa}$. This shows that the flax fibers at outer layers are more beneficial for impact loading, where they possibly hinder linear crack propagation [15]. Furthermore, the hybrid composites with outer plies from flax deliver higher mechanical and impact absorption than the hybrid composites with outer carbon plies (the overall number of carbon and flax is the same) [15]. Use of two carbon UD prepregs on the outer layers of carbon/flax composites leads to a tensile failure of the carbon ply followed by progressive delamination and buckling of the flax plies [9]. Introduction of carbon plies in the middle and outer layers of the hybrid carbon/flax composite results in a compression failure of carbon independently of the fiber fraction [17]. Scanning electron microscopy shows that both hybrid carbon/flax composites with UD and twill flax prepregs show mainly matrix cracking and fiber pullout. Furthermore, this failure is accompanied with delamination, fiber tearing, and breakage [13].

The ranking of the bending strength and bending modulus of carbon/flax composites including the residual flexural properties is represented in Figures 4 and 5, respectively. In the case of bending strength, the advantageous behaviour of hybrid composites in comparison with flax fiber-epoxy composites is obvious. In addition, via accurate selection of the reinforcement type, for both carbon and flax, it is possible to develop a carbon/flax composite with the bending properties in the field of carbon-epoxy composites, namely, higher than $500 \mathrm{MPa}$.

In the case of the bending modulus, Figure 5, the benefit of the hybridisation of carbon and flax is even more pronounced. The hybrid composites result in equal or higher bending modulus in comparison with nonhybrid carbon composites and significantly higher than the bending modulus of nonhybrid flax composites.

\section{Damping Properties}

Damping capacity is an important parameter for materials employed in structural applications, where these materials are subjected to undesired vibrations during operation. 


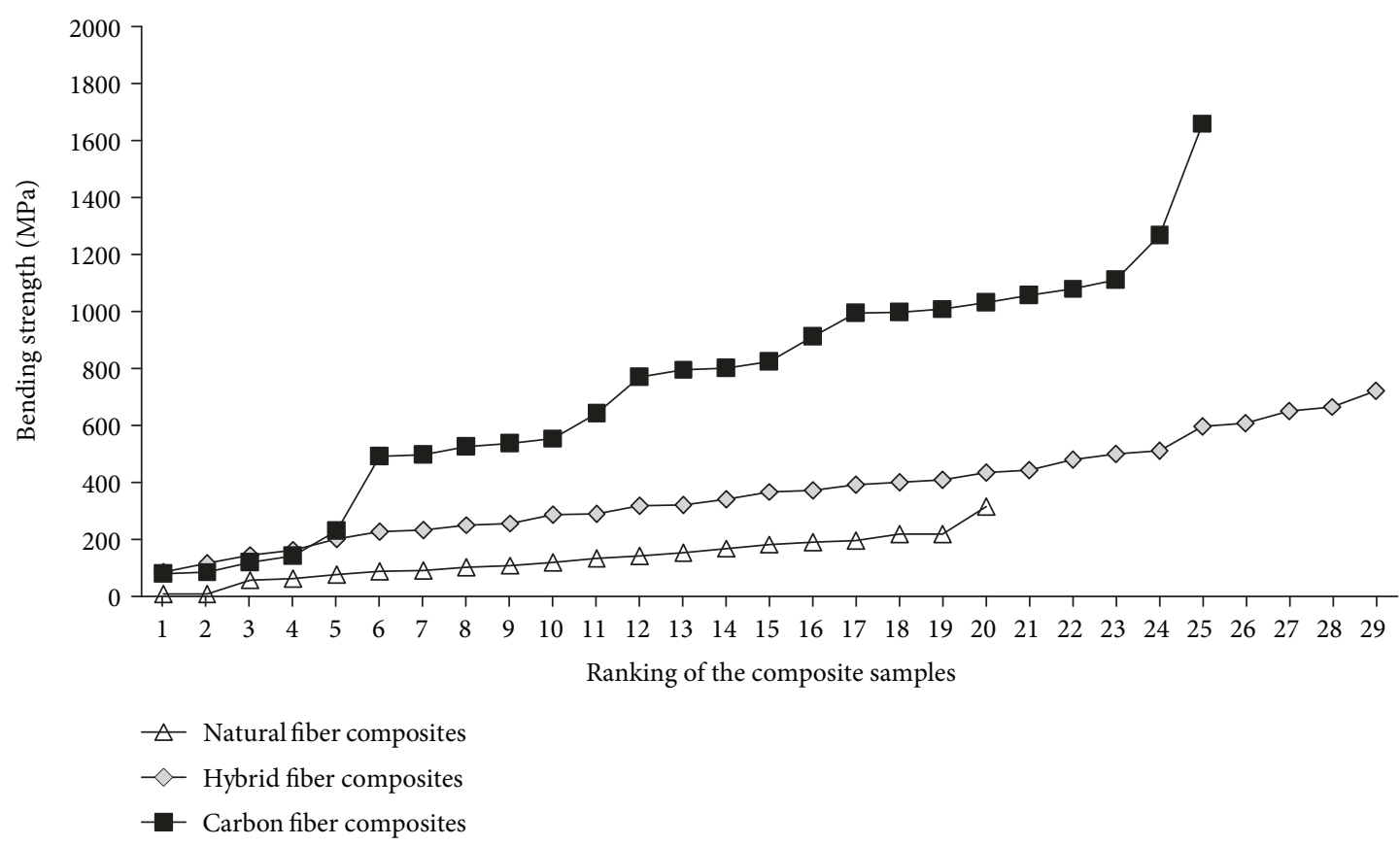

FIGURE 4: Bending strength of various hybrid carbon-/flax- and nonhybrid flax- or carbon-epoxy composites $[8,9,12,13,15,17,21,22,26$, $40,43,45,46,51-55]$.

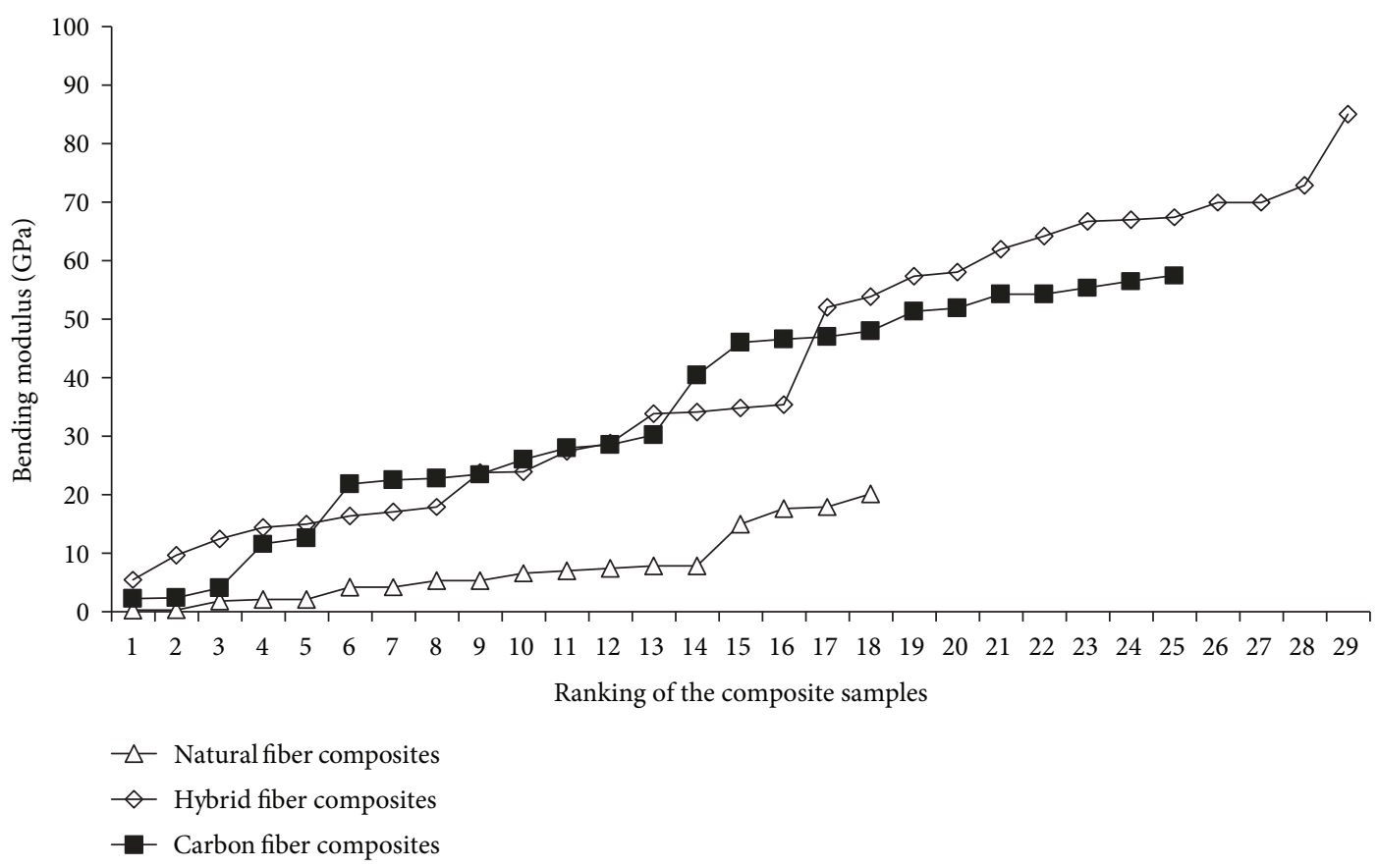

FIGURE 5: Bending modulus of hybrid carbon-/flax- and nonhybrid carbon- and flax-epoxy composites $[8,9,12,13,15,17,21,22,26,40,43$, $45,46,51-55]$.

Materials with low damping capacity transmit readily sound and vibration, e.g., steel or aluminium. Hybridisation of different fibers as a common method for improving damping characteristics in synthetic laminate composites is broadly discussed in the literature [56].

A hybridisation of carbon with flax fibers to improve the damping properties of carbon composites is promoted by the high damping ratio of flax fibers in comparison with titanium, aluminium, steel, or carbon [8]. Furthermore, the damping of nonhybrid flax fiber laminates is significantly higher than the damping coefficients of nonhybrid carbon fiber laminates [24]. Particularly, the damping coefficient of composites reinforced with flax fibers is found to be 4 times higher than that of composites reinforced with carbon fiber 
[18]. This beneficial damping effect of flax fibers in polymer composites is directly related to the multiple structure of the flax fibers $[17,57]$. Specifically, flax fibers consist of yarns of elementary fibers, each being composed of cell walls in which rigid cellulose microfibrills are embedded in a soft lignin and hemicellulose matrix. All of these flax components differ in their chemical composition, mass ratios, and morphology. Therefore, through friction between and within the cell walls, the structure of flax fibers promotes dissipation of energy and leads to an enhanced intrinsic damping in comparison with synthetic fibers [57]. Among various methods available for the testing of damping, free flexural vibration testing is mostly used in the case of the reported carbon/flax hybrid composites [8, 14, 17, 18, 24].

The reported results show that the damping properties of carbon-/flax-epoxy composites depend on the fiber content, stacking sequence, and fiber direction. Furthermore, it is possible to predict damping properties of hybrid composites using various models.

The hybridisation of flax and carbon in one composite results in a damping capacity higher than that of carbon but lower than that of nonhybrid flax composites [14]. However, after a critical flax fiber volume fraction of $40 \%$, the damping starts to decrease [17]. This damping decrease by the critical volume fraction is possibly related to the poor compatibility of flax and epoxy [17].

Besides the flax fiber content, the stacking sequence has a significant influence on the damping properties of carbon/flax composites. The hybrid composites with outer layers made of carbon fibers have lower damping than the hybrid composites with outer layers made of flax, since the energy dissipation is directed mainly by external layers of the composites $[14,24]$. In comparison with nonhybrid carbon composites, the damping of a hybrid composite with outer layers made of carbon is about $6 \%$ higher. At the same time, the hybrid composite with outer layers made of flax is $196 \%$ higher than that of the nonhybrid carbon composite [14].

Analysis of damping properties of the nonhybrid and hybrid UD composites as a function of fiber alignment shows that the result is also dependent on both fiber material and stacking sequence. As an example, in the case of UD nonhybrid flax composites and UD hybrid carbon/flax composites with outer flax layers, the maximum damping is achieved in the case of the $75^{\circ}$ fiber alignment. On the other hand, in the case of UD nonhybrid carbon fiber composites and UD hybrid carbon/flax composites with outer carbon layers, the highest damping is achieved in the $45^{\circ}$ fiber alignment [24].

Moreover, there is a good correlation between the experimental and predicted damping properties. Particularly, using the finite element analysis of the carbon/flax composites, it is possible to evaluate the energy dissipation within each layer in the hybrid composite [14] or as a function of fiber direction $[14,24]$. Furthermore, an effective correlation between elastic modulus and vibration damping of a hybrid composite is described using a rule of hybrid mixtures and laminate theory based on the properties of the nonhybrid carbon and flax composites [18].

An application-specific study on the use of carbon/flax composite material for a bicycle frame shows that the achieved damping properties are better than all common frame materials [8].

\section{Impact Properties}

Impact properties provide information about the energy absorbed by a material during fracture. Incorporation of small amounts of fibers with low modulus and high strength is an already described way to improve the impact properties of high performance composites, e.g., introduction of glass fibers into graphite composites [58]. Hybridisation of carbon and flax in order to improve the impact behaviour of carbon composites is promoted by the high toughness of the flax fibers. At the same time, the impact properties of nonhybrid carbon and flax composites are strongly dependent on the testing methods, e.g., Charpy impact testing or drop-weight testing.

The impact strength defined by the Charpy impact test shows that the flax composite has a low impact strength of $38.4 \mathrm{~kJ} / \mathrm{m}^{2}$, whereas the impact strength of carbon is nearly $820 \%$ higher [17]. According to the authors, these results are induced by the mechanical properties of fibers and the fiber-matrix adhesion in a composite. Particularly, flax composites show a dual-natured failure mode, consisting of fiber breakage accompanied with a fiber pullout from the matrix and a local fiber debonding from the matrix [17]. Both of these failure modes promote dissipation of energy during the impact testing. However, due to the low fiber-matrix adhesion and low mechanical properties of natural fibers, the overall energy absorption is low. On the other hand, carbon composites possess several failure modes, whereas two primary failure modes are fiber debonding and fiber breakage [17]. Since the fiber-matrix adhesion in carbon composites is better than in natural fiber composites, a greater energy dissipation takes places during the fiber-debonding event. Similarly, due to the higher mechanical properties of carbon fibers, more energy is required to break a carbon fiber than a flax fiber [17]. However, impact testing using drop-weight shows that nonhybrid flax composites possess better energy absorption than the nonhybrid carbon composites and thus results in a high damage development in comparison with carbon fiber composites [15]. According to this study, this behaviour is attributed to the additional damage mechanisms such as debonding, fibrillation, and pull-out phenomena in flax composites.

Regarding the impact properties of hybrid carbon/flax composites, both flax fiber content and the stacking sequence significantly affect the results. The comparison of two carbon/flax composites shows that the hybrid composites with outer layers made of flax have better mechanical and impact absorption than those with outer carbon layers [15]. In the case of hybrid composites with outer carbon plies, the amount of $10 \%$ flax inside the composite results in the increase of impact strength (Charpy impact) compared with the nonhybrid carbon composite, but the further increase of flax content leads to the decrease of impact strength [17]. The drop-weight impact testing of hybrid carbon/basalt/flax composites with outer carbon plies and varied stacking sequence of basalt and flax fibers inside the composite shows 
that the mean value of the impact penetration energy is not influenced [21]. However, the alternating stacking sequence, namely, carbon-flax-basalt-flax-basalt-flax-carbon in comparison with carbon-basalt-flax-basalt-carbon shows higher standard deviation of the single specimen values showing that the complexity of the composite has been enhanced [21].

\section{Modelling Approaches}

Various modelling approaches have been studied in order to predict the properties of the hybrid carbon-/flax-epoxy composites: rule of mixtures [17], rule of hybrid mixtures [18, 25], Halpin-Tsai method [17], and finite element analysis $[14,24]$. These approaches can be described briefly as follows:

(i) The rule of mixtures is the simplest method, which is usually applied for the prediction of the properties of a nonhybrid fiber-reinforced composite. In this case, the property of the composite depends merely on the individual properties of the composite components and their volume fractions in the composite. As an example, the tensile modulus of a composite depends merely on the tensile moduli of the fibers and matrix and their volume fractions in the composite. The rule of hybrid mixtures can be described as a derivative of the rule of mixtures. However, this approach is applied for hybrid composites consisting of two fiber types. In this case, it is assumed that the hybrid composite is a system consisting of two single composites, which do not interact. Consequently, in this case, the modulus of the hybrid composite is estimated as a sum of the moduli of the two composites considering their volume fraction in the hybrid composite [59]. Generally, this approach is used for short fiber hybrid composites [60]

(ii) The Halpin-Tsai equations represent a set of empirical relationships based on the "self-consistent micromechanics method" [61]. These equations can be used for the estimation of the composite elasticity in terms of the individual properties of the matrix and reinforcing fibers considering their volume fractions and geometry. As an example, the Halpin-Tsai approach demonstrates a significant effect of a reinforcement geometry on the stiffness of a UD ply, even if the volume fraction and packing geometry are constant. A broad description of the Halpin-Tsai equations is presented in the literature [61].

(iii) The finite element method (FEM) is an established application-oriented computer simulation approach used for conceptualisation and development of physical properties. The basic principle of the finite element analysis is that the volume or surface of the analyzed object is divided into smaller bodies or units (finite elements). Consequently, a physical property of the complete object, e.g., its stiffness, can be described as a sum of the finite elements' matrix each having a certain stiffness. Besides the values of the finite element properties, the geometry of the object and the loading are taken in account. The finite elements' matrix related to the geometrical parameters of the object and applied loads provides a linear system of equations with unknowns representing deformations at the joining points. The solution of these equations enables calculation of the load at each individual finite element. [62]

These models have been used in order to study mechanical $[17,18,25]$ and damping properties $[14,18,24]$ of the reported carbon/flax fiber hybrid composites. In general, all of the predicted values show good agreement with the experimental results. At the same time, several tendencies can be emphasised. Firstly, the increase of the plain-weaved flax fiber content increases the difference between the experimental and predicted modulus values, e.g., from 2 to $12 \%$ in the case of the Halpin-Tsai method and the rule of mixtures' model [17]. According to the authors, this is explained by the deviations of the alignment of the flax fibers, which occurs during fiber processing, so the fibers are wound together rather than straight and inline. Secondly, it has been shown that the Halpin-Tsai method delivers more accurate prediction of elastic modulus than the rule of mixtures at flax fiber volumes lower than 15\% [17]. The accuracy of the methods is determined by comparing the coefficients of variance. According to the study, this behaviour is explained by the additional parameters taken into account by the HalpinTsai method. At the same time, the higher content of flax fibers leads to lower prediction accuracy. Thirdly, the stiffness of the hybrid composites exhibiting linear behaviour, which is predicted using the rule of hybrid mixture, is within $10 \%$ of experimental values [25].

A close agreement of the experimentally obtained and predicted (FEM) damping properties and energy dissipation values is reported within the hybrid composite layers [24]. The calculation of the loss coefficient is based on the tradeoff between the elastic modulus and damping of the carbon/flax composite. The damping is described as the elastic energy stored and multiplied by the amount of the energy dissipated over one radian of a vibration cycle and expressed over to the total stored energy [18]. However, in this case, the experimentally determined values of elastic modulus and loss coefficient and those predicted using the rule of hybrid mixtures are strongly depending on the stacking sequence and amount of flax fibers. Lower amount of the flax fibers leads to the minimal difference between the predicted and experimentally determined values, namely, $1 \%$ for the elastic modulus and 3\% for loss coefficient [18].

\section{Summary and Outlook}

The aim of this review is to provide a systematic summary about the recent progress in the development of carbon/flax composites. This article includes information about the application fields, materials, and manufacturing techniques 
as well as tensile, bending, damping, and impact properties of carbon/flax composites.

This review shows that the following parameters mainly determine the mechanical and damping properties of the resulting hybrid carbon/flax fiber composites: amount of the fibers and stacking sequence in the case of textiles and the type of the special distribution in the case of the short fibers. Furthermore, type of the textile (twill, plain, or UD) also has an effect on the mechanical properties and failure mechanisms in the hybrid composites. The results show that using an accurate adjustment of the stacking sequence and fiber fraction in the hybrid composites, it is possible to realize high tensile and high bending properties, which are competitive with those of the nonhybrid carbon composites. Additionally, the type of used textiles and the areal weight play an important role. Finally, it is possible to predict mechanical and damping properties of the hybrid carbon/flax composites using various models, like the rule of mixtures, Halpin-Tsai, or FEM.

However, certain fiber fractions and stacking sequences can show a positive effect on one property and a negative effect on another. As an example, the introduction of flax properties in a nonhybrid carbon composite leads to the improvement of damping and impact properties but shows lower tensile and bending strength. A further example is that positioning flax fibers at the outer layers in hybrid composites is advantageous for impact properties, whereas outer layers made of carbon fibers offer higher stiffness.

To sum up, the carbon/flax composites offer a great application-oriented potential for lightweight industries. These hybrid composites have very good mechanical performance and damping properties. Using the above-mentioned parameters, it is possible to adjust the mechanical and damping properties with regard to a certain application. Nevertheless, there are still several challenges associated with the systematic representation of the diverse types and forms of the used composite constituents as well as some questions related to the morphology of natural fibers. In order to overcome these challenges, the research on analytical methods regarding consistent characterization of natural fibers should be carried out. Furthermore, development of natural fiber reinforcements with stable and reproducible properties, including specially developed surface treatment, adjusted weaving art, yarn fineness, and twisting grade, would improve the compatibility of fibers in the hybrid composites and thus further improve their properties.

\section{Conflicts of Interest}

The authors declare that there is no conflict of interest regarding the publication of this paper.

\section{Acknowledgments}

This study was implemented in the scope of the project "Functionally-integrated, three-dimensional variable production of bio-hybrid components with maximum biobased content (ProBio)" funded by the Ministry for Science and Culture of the State of Lower Saxony (MWK).

\section{References}

[1] F. M. AL-Oqla and S. M. Sapuan, "Natural fiber reinforced polymer composites in industrial applications: feasibility of date palm fibers for sustainable automotive industry," Journal of Cleaner Production, vol. 66, pp. 347-354, 2014.

[2] O. Faruk, A. K. Bledzki, H.-P. Fink, and M. Sain, "Progress report on natural fiber reinforced composites," Macromolecular Materials and Engineering, vol. 299, no. 1, pp. 9-26, 2014.

[3] L. Mohammed, M. N. M. Ansari, G. Pua, M. Jawaid, and M. S. Islam, "A review on natural fiber reinforced polymer composite and its applications," International Journal of Polymer Science, vol. 2015, no. 2, Article ID 243947, 15 pages, 2015.

[4] M. R. Sanjay, P. Madhu, M. Jawaid, P. Senthamaraikannan, S. Senthil, and S. Pradeep, "Characterization and properties of natural fiber polymer composites: a comprehensive review," Journal of Cleaner Production, vol. 172, pp. 566-581, 2018.

[5] K. L. Pickering, M. G. A. Efendy, and T. M. Le, "A review of recent developments in natural fibre composites and their mechanical performance," Composites Part A: Applied Science and Manufacturing, vol. 83, pp. 98-112, 2016.

[6] S. Mishra, A. K. Mohanty, L. T. Drzal et al., "Studies on mechanical performance of biofibre/glass reinforced polyester hybrid composites," Composites Science and Technology, vol. 63, no. 10, pp. 1377-1385, 2003.

[7] M. Jawaid and H. P. S. Abdul Khalil, "Cellulosic/synthetic fibre reinforced polymer hybrid composites: a review," Carbohydrate Polymers, vol. 86, no. 1, pp. 1-18, 2011.

[8] A. Amiri, T. Krosbakken, W. Schoen, D. Theisen, and C. A. Ulven, "Design and manufacturing of a hybrid flax/carbon fiber composite bicycle frame," Proceedings of the Institution of Mechanical Engineers, Part P: Journal of Sports Engineering and Technology, vol. 232, no. 1, pp. 28-38, 2017.

[9] Z. S. Bagheri, I. El Sawi, E. H. Schemitsch, R. Zdero, and H. Bougherara, "Biomechanical properties of an advanced new carbon/flax/epoxy composite material for bone plate applications," Journal of the Mechanical Behavior of Biomedical Materials, vol. 20, pp. 398-406, 2013.

[10] Bioplastics Magazine, "Conference in biobased materials for automotive applications," https://www.bioplasticsmagazine .com/en/events/bio-car/.

[11] O. Hansen, C. Habermann, and H.-J. Endres, "Bio-based materials for exterior applications - project BioHybridCar," in Technologies for economical and functional lightweight design, Zukunftstechnologien für den multifunktionalen Leichtbau, pp. 189-200, Springer, 2019.

[12] V. Fiore, A. Valenza, and G. di Bella, "Mechanical behavior of carbon/flax hybrid composites for structural applications," Journal of Composite Materials, vol. 46, no. 17, pp. 20892096, 2012.

[13] H. N. Dhakal, Z. Y. Zhang, R. Guthrie, J. MacMullen, and N. Bennett, "Development of flax/carbon fibre hybrid composites for enhanced properties," Carbohydrate Polymers, vol. 96, no. 1, pp. 1-8, 2013.

[14] M. Assarar, W. Zouari, H. Sabhi, R. Ayad, and J.-M. Berthelot, "Evaluation of the damping of hybrid carbon-flax reinforced composites," Composite Structures, vol. 132, pp. 148-154, 2015.

[15] F. Sarasini, J. Tirillò, S. D'Altilia et al., "Damage tolerance of carbon/flax hybrid composites subjected to low velocity impact," Composites Part B: Engineering, vol. 91, pp. 144153,2016 
[16] M. Karray, A. Triki, C. Poilâne, P. Picart, and M. Gargouri, "Influence of two carbon plies on adhesion of unidirectional flax-fibers reinforced epoxy composites," Polymer Composites, vol. 37, no. 1, pp. 241-253, 2016.

[17] J. Flynn, A. Amiri, and C. Ulven, "Hybridized carbon and flax fiber composites for tailored performance," Materials \& Design, vol. 102, pp. 21-29, 2016.

[18] M. J. Le Guen, R. H. Newman, A. Fernyhough, G. W. Emms, and M. P. Staiger, "The damping-modulus relationship in flax-carbon fibre hybrid composites," Composites Part B: Engineering, vol. 89, pp. 27-33, 2016.

[19] M. Fehri, R. R. Ragueh, A. Vivet, F. Dammak, and M. Haddar, "Improvement of natural fiber composite materials by carbon fibers," Journal of Renewable Materials, vol. 5, no. 1, pp. 38-47, 2017.

[20] R. V. Prakash and M. Maharana, "Damage detection using infrared thermography in a carbon-flax fiber hybrid composite," Procedia Structural Integrity, vol. 7, pp. 283-290, 2017.

[21] E. Nisini, C. Santulli, and A. Liverani, "Mechanical and impact characterization of hybrid composite laminates with carbon, basalt and flax fibres," Composites Part B: Engineering, vol. 127, pp. 92-99, 2017.

[22] M. Shamsuyeva and H. J. Endres, "Polyelectrolyte treatment of cellulose fibers for the manufacture of novel bio-hybrid fiber composites (Bio-HFC) for lightweight applications," Key Engineering Materials, vol. 742, pp. 389-394, 2017.

[23] M. L. Longana, V. Ondra, H. N. Yu, K. D. Potter, and I. Hamerton, "Reclaimed carbon and flax fibre composites: manufacturing and mechanical properties," Recycling, vol. 3, no. 4, p. 52, 2018.

[24] M. Ben Ameur, A. El Mahi, J.-L. Rebiere, M. Abdennadher, and M. Haddar, "Damping analysis of unidirectional carbon/flax fiber hybrid composites," International Journal of Applied Mechanics, vol. 10, no. 5, article 1850050, 2018.

[25] U. Kureemun, M. Ravandi, L. Q. N. Tran, W. S. Teo, T. E. Tay, and H. P. Lee, "Effects of hybridization and hybrid fibre dispersion on the mechanical properties of woven flax-carbon epoxy at low carbon fibre volume fractions," Composites Part B: Engineering, vol. 134, pp. 28-38, 2018.

[26] J. Bachmann, M. Wiedemann, and P. Wierach, "Flexural mechanical properties of hybrid epoxy composites reinforced with nonwoven made of flax fibres and recycled carbon fibres," Aerospace, vol. 5, no. 4, p. 107, 2018.

[27] M. Ben Ameur, A. el Mahi, J.-L. Rebiere, M. Beyaoui, M. Abdennadher, and M. Haddar, "Tensile fatigue behavior of carbon-flax/epoxy hybrid composites," in Advances in Acoustics and Vibration II. ICAV 2018, T. Fakhfakh, C. Karra, S. Bouaziz, F. Chaari, and M. Haddar, Eds., vol. 13 of Applied Condition Monitoring, pp. 284-291, Springer International Publishing, Cham, 2019.

[28] G. W. Ehrenstein, Faserverbund-Kunststoffe: Werkstoffe, Verarbeitung, Eigenschaften. 2. völlig überarb. Aufl, Hanser, München, 2006.

[29] P. K. Mallick, Fiber-Reinforced Composites: Materials, Manufacturing, and Design, CRC Press, Boca Raton, Fla, 3 ed edition, 2008.

[30] D. Zenkert, An Introduction to Sandwich Construction. [Reprinted with Minor Amendments], EMAS, Warley, 1997.

[31] C. Cherif, Textile Materials for Lightweight Constructions: Technologies - Methods - Materials - Properties, Springer, Heidelberg, 2016.
[32] F. Denninger, Lexikon technische Technische Textilien, Dt. Fachverl, Frankfurt am Main, 2009, Edition Textil.

[33] M. Le Gall, P. Davies, N. Martin, and C. Baley, "Recommended flax fibre density values for composite property predictions," Industrial Crops and Products, vol. 114, pp. 52-58, 2018.

[34] D. Hull and T. W. Clyne, An Introduction to Composite Materials, Cambridge solid state science series, Cambridge University Press, Cambridge, 2. Ed., Reprinted edition, 2001.

[35] D. U. Shah, Characterisation and Optimisation of the Mechanical Performance of Plant Fibre Composites for Structural Applications, University of Nottingham. Ph.D. Thesis, Nottingham, UK, 2013.

[36] S.-J. Park, Carbon Fibers, vol. 210 of Springer series in materials science, Springer, Singapore, 2nd ed edition, 2018.

[37] C. Baley, A. le Duigou, A. Bourmaud, and P. Davies, "Influence of drying on the mechanical behaviour of flax fibres and their unidirectional composites," Composites Part A: Applied Science and Manufacturing, vol. 43, no. 8, pp. 1226-1233, 2012.

[38] R. J. C. Carbas, L. F. M. da Silva, E. A. S. Marques, and A. M. Lopes, "Effect of post-cure on the glass transition temperature and mechanical properties of epoxy adhesives," Journal of Adhesion Science and Technology, vol. 27, no. 23, pp. 25422557, 2013.

[39] D. G. Lee and N. P. Suh, Axiomatic Design and Fabrication of Composite Structures: Applications in Robots, Machine Tools and Automobiles, Oxford series on advanced manufacturing, Oxford University Press, New York, 2006.

[40] H. Rahmani, S. H. M. Najafi, S. Saffarzadeh-Matin, and A. Ashori, "Mechanical properties of carbon fiber/epoxy composites: effects of number of plies, fiber contents, and angle-ply layers," Polymer Engineering \& Science, vol. 54, no. 11, pp. 2676-2682, 2014.

[41] J. M. F. de Paiva, S. Mayer, and M. C. Rezende, "Comparison of tensile strength of different carbon fabric reinforced epoxy composites," Materials Research, vol. 9, no. 1, pp. 83-90, 2006.

[42] S. Ekşı and K. Genel, "Comparison of mechanical properties of unidirectional and woven carbon, glass and aramid fiber reinforced epoxy composites," Acta Physica Polonica A, vol. 132, no. 3-II, pp. 879-882, 2017.

[43] C. Cerbu, "Mechanical characterization of the flax/epoxy composite material," Procedia Technology, vol. 19, pp. 268-275, 2015.

[44] J. George and J. I.,. I. Verpoest, "Mechanical properties of flax fibre reinforced epoxy composites," Die Angewandte Makromolekulare Chemie, vol. 272, no. 1, pp. 41-45, 1999.

[45] I. van de Weyenberg, J. Ivens, A. de Coster, B. Kino, E. Baetens, and I. Verpoest, "Influence of processing and chemical treatment of flax fibres on their composites," Composites Science and Technology, vol. 63, no. 9, pp. 1241-1246, 2003.

[46] S. Goutianos, T. Peijs, B. Nystrom, and M. Skrifvars, "Development of flax fibre based textile reinforcements for composite applications," Applied Composite Materials, vol. 13, no. 4, pp. 199-215, 2006.

[47] K. Oksman, "High quality flax fibre composites manufactured by the resin transfer moulding process," Journal of Reinforced Plastics and Composites, vol. 20, no. 7, pp. 621-627, 2001.

[48] W. Gindl-Altmutter, J. Keckes, J. Plackner, F. Liebner, K. Englund, and M.-P. Laborie, "All-cellulose composites prepared from flax and lyocell fibres compared to epoxy-matrix composites," Composites Science and Technology, vol. 72, no. 11, pp. 1304-1309, 2012. 
[49] Z. Mahboob, I. el Sawi, R. Zdero, Z. Fawaz, and H. Bougherara, "Tensile and compressive damaged response in Flax fibre reinforced epoxy composites," Composites Part A: Applied Science and Manufacturing, vol. 92, pp. 118-133, 2017.

[50] M. Kersani, S. V. Lomov, A. W. van Vuure, A. Bouabdallah, and I. Verpoest, "Damage in flax/epoxy quasi-unidirectional woven laminates under quasi-static tension," Journal of Composite Materials, vol. 49, no. 4, pp. 403-413, 2014.

[51] J. Meredith, S. R. Coles, R. Powe et al., "On the static and dynamic properties of flax and Cordenka epoxy composites," Composites Science and Technology, vol. 80, pp. 31-38, 2013.

[52] M. E. Islam, T. H. Mahdi, M. V. Hosur, and S. Jeelani, "Characterization of carbon fiber reinforced epoxy composites modified with nanoclay and carbon nanotubes," Procedia Engineering, vol. 105, pp. 821-828, 2015.

[53] I. van de Weyenberg, T. Chi Truong, B. Vangrimde, and I. Verpoest, "Improving the properties of UD flax fibre reinforced composites by applying an alkaline fibre treatment," Composites Part A: Applied Science and Manufacturing, vol. 37, no. 9, pp. 1368-1376, 2006.

[54] S. Phillips, J. Baets, L. Lessard, P. Hubert, and I. Verpoest, "Characterization of flax/epoxy prepregs before and after cure," Journal of Reinforced Plastics and Composites, vol. 32, no. 11, pp. 777-785, 2013.

[55] L. Yan, N. Chouw, and X. Yuan, "Improving the mechanical properties of natural fibre fabric reinforced epoxy composites by alkali treatment," Journal of Reinforced Plastics and Composites, vol. 31, no. 6, pp. 425-437, 2012.

[56] R. Chandra, S. P. Singh, and K. Gupta, "Damping studies in fiber-reinforced composites - a review," Composite Structures, vol. 46, no. 1, pp. 41-51, 1999.

[57] F. Duc, P. E. Bourban, C. J. G. Plummer, and J.-A. E. Månson, "Damping of thermoset and thermoplastic flax fibre composites," Composites Part A: Applied Science and Manufacturing, vol. 64, pp. 115-123, 2014.

[58] B. D. Agarwal, L. J. Broutman, and K. Chandrashekhara, Anal$y$ sis and Performance of Fiber Composites, Wiley, Hoboken, NJ, Fourth edition edition, 2018.

[59] M. John and S. Thomas, "Biofibres and biocomposites," Carbohydrate Polymers, vol. 71, no. 3, pp. 343-364, 2008.

[60] J. Mirbagheri, M. Tajvidi, J. C. Hermanson, and I. Ghasemi, "Tensile properties of wood flour/kenaf fiber polypropylene hybrid composites," Journal of Applied Polymer Science, vol. 105, no. 5, pp. 3054-3059, 2007.

[61] J. C. H. Affdl and J. L. Kardos, "The Halpin-Tsai equations: a review," Polymer Engineering \& Science, vol. 16, no. 5, pp. 344-352, 1976.

[62] B. Klein, FEM: Grundlagen und Anwendungen der FiniteElement-Methode im Maschinen- und Fahrzeugbau; mit 12 Fallstudien und 20 Übungsaufgaben. 8., verbesserte und erweiterte Auflage, Vieweg + Teubner, Wiesbaden, 2010. 


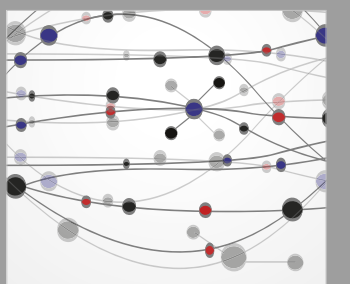

The Scientific World Journal
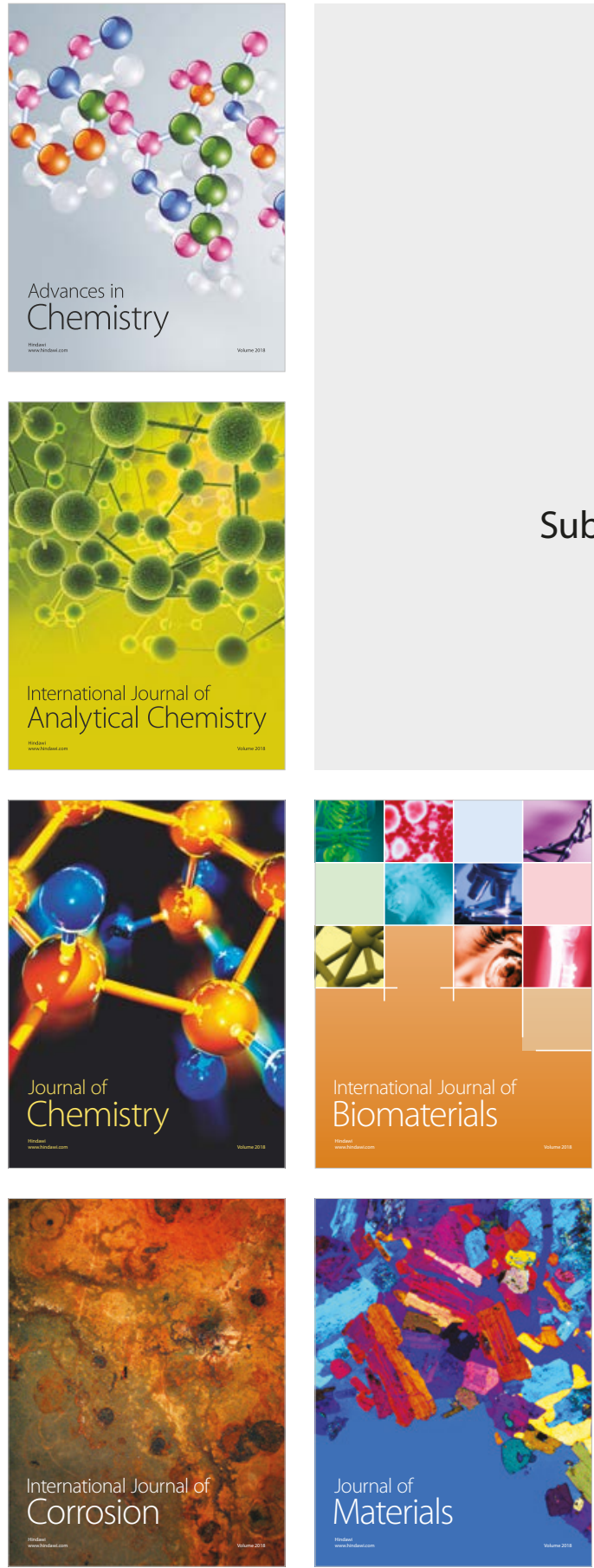

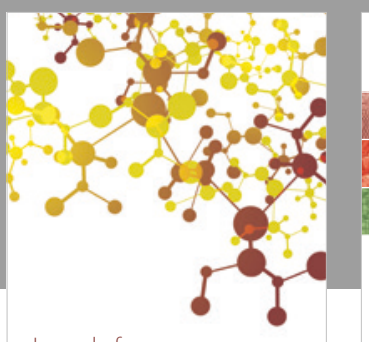

Journal of

Applied Chemistry
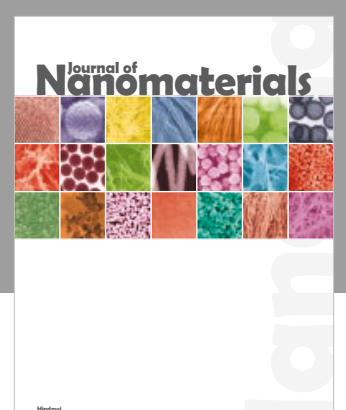

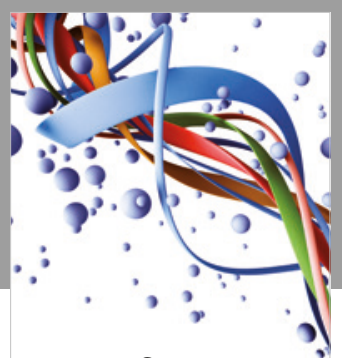

Scientifica

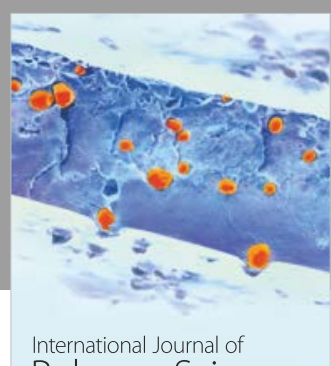

Polymer Science

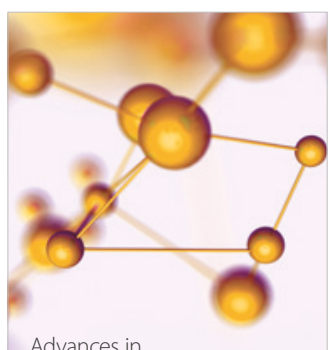

Physical Chemistry
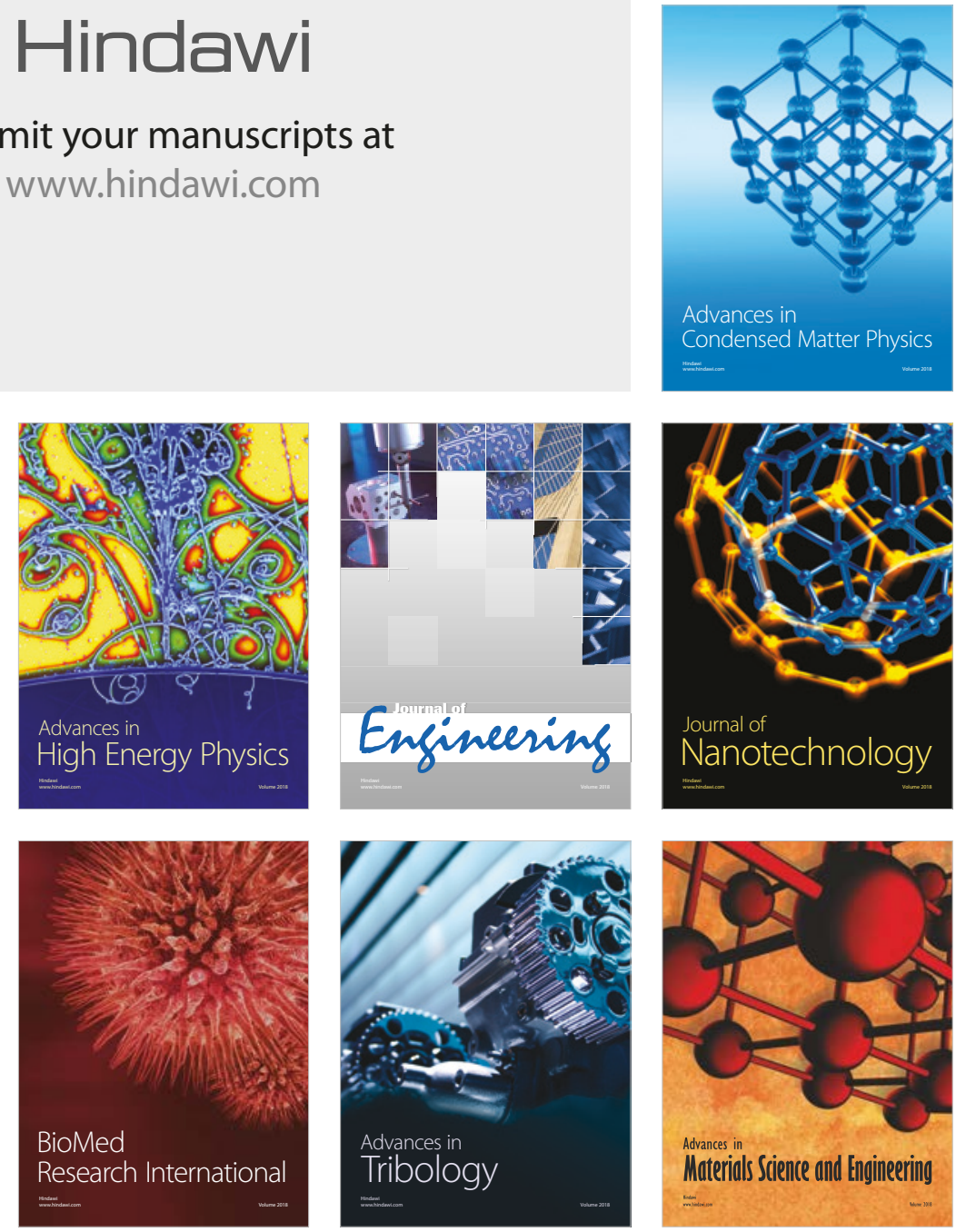